\title{
Seasonal variability and source apportionment of volatile organic compounds (VOCs) in the Paris megacity (France)
}

\author{
Alexia Baudic ${ }^{1}$, Valérie Gros ${ }^{1}$, Stéphane Sauvage $^{2}$, Nadine Locoge $^{2}$, Olivier Sanchez ${ }^{3}$, Roland Sarda-Estève ${ }^{1}$, \\ Cerise Kalogridis $^{1, \mathrm{a}}$, Jean-Eudes Petit ${ }^{1,4, \mathrm{~b}}$, Nicolas Bonnaire ${ }^{1}$, Dominique Baisnée ${ }^{1}$, Olivier Favez $^{4}$, \\ Alexandre Albinet ${ }^{4}$, Jean Sciare ${ }^{1, c}$, and Bernard Bonsang ${ }^{1}$ \\ ${ }^{1}$ LSCE, Laboratoire des Sciences du Climat et de l'Environnement, Unité Mixte CEA-CNRS-UVSQ, \\ CEA/Orme des Merisiers, 91191 Gif-sur-Yvette, France \\ ${ }^{2}$ Mines Douai, Département Sciences de l'Atmosphère et Génie de l'Environnement (SAGE), 59508 Douai, France \\ ${ }^{3}$ AIRPARIF, Association Agréée de Surveillance de la Qualité de l'Air en Île-de-France, 75004 Paris, France \\ ${ }^{4}$ INERIS, Institut National de l'EnviRonnement Industriel et des risqueS, DRC/CARA/CIME, Parc Technologique Alata, \\ BP2, 60550 Verneuil-en-Halatte, France \\ anow at: Institute of Nuclear Technology and Radiation Protection, Environmental Radioactivity Laboratory, \\ National Center of Scientific Research Demokritos, 15310 Ag. Paraskevi, Attiki, Greece \\ ${ }^{b}$ now at: Air Lorraine, 20 rue Pierre Simon de Laplace, 57070 Metz, France \\ ${ }^{c}$ now at: Energy Environment Water Research Center (EEWRC), The Cyprus Institute, Nicosia, Cyprus
}

Correspondence to: Valérie Gros (valerie.gros@1sce.ipsl.fr)

Received: 2 March 2016 - Published in Atmos. Chem. Phys. Discuss.: 7 April 2016

Revised: 31 August 2016 - Accepted: 1 September 2016 - Published: 26 September 2016

\begin{abstract}
Within the framework of air quality studies at the megacity scale, highly time-resolved volatile organic compound $\left(\mathrm{C}_{2}-\mathrm{C}_{8}\right)$ measurements were performed in downtown Paris (urban background sites) from January to November 2010. This unique dataset included non-methane hydrocarbons (NMHCs) and aromatic/oxygenated species (OVOCs) measured by a GC-FID (gas chromatograph with a flame ionization detector) and a PTR-MS (proton transfer reaction - mass spectrometer), respectively. This study presents the seasonal variability of atmospheric VOCs being monitored in the French megacity and their various associated emission sources. Clear seasonal and diurnal patterns differed from one VOC to another as the result of their different origins and the influence of environmental parameters (solar radiation, temperature). Source apportionment (SA) was comprehensively conducted using a multivariate mathematical receptor modeling. The United States Environmental Protection Agency's positive matrix factorization tool (US EPA, PMF) was used to apportion and quantify ambient VOC concentrations into six different sources. The modeled source profiles were identified from near-field observations (measurements from three distinct emission sources: inside a
\end{abstract}

highway tunnel, at a fireplace and from a domestic gas flue, hence with a specific focus on road traffic, wood-burning activities and natural gas emissions) and hydrocarbon profiles reported in the literature. The reconstructed VOC sources were cross validated using independent tracers such as inorganic gases $\left(\mathrm{NO}, \mathrm{NO}_{2}, \mathrm{CO}\right)$, black carbon $(\mathrm{BC})$ and meteorological data (temperature). The largest contributors to the predicted VOC concentrations were traffic-related activities (including motor vehicle exhaust, $15 \%$ of the total mass on the annual average, and evaporative sources, $10 \%$ ), with the remaining emissions from natural gas and background $(23 \%)$, solvent use $(20 \%)$, wood-burning (18\%) and a biogenic source $(15 \%)$. An important finding of this work is the significant contribution from wood-burning, especially in winter, where it could represent up to $\sim 50 \%$ of the total mass of VOCs. Biogenic emissions also surprisingly contributed up to $\sim 30 \%$ in summer (due to the dominating weight of OVOCs in this source). Finally, the mixed natural gas and background source exhibited a high contribution in spring (35\%, when continental air influences were observed) and in autumn (23\%, for home heating consumption). 


\section{Introduction}

More than half of the world's population is now living in urban areas and about $70 \%$ will be city dwellers by 2050 (United Nations, 2014). Many of these urban centers are ever expanding, leading to the gradual growth of megacities. Strong demographic and economic pressures are exerting increasing stress on the natural environment, with impacts at local, regional and global scales. Megacities are hotspots of atmospheric gaseous and particulate pollutants, which are subjects of concern for sanitary, scientific, economic, societal and political reasons. The adverse health effects of outdoor air pollutants are recognized today. Indeed, ambient air pollution has been classified as carcinogenic to humans by the International Agency for Research on Cancer since October 2013 (IARC, 2013). In recent decades, air pollution has become one of the most widespread problems in many megacities and should be more investigated.

The understanding of the pollutants in urban areas remains complex given the diversity of their emission sources (unequally distributed in space and time) as well as their formation and transformation processes. Volatile organic compounds (VOCs) are of a great scientific interest because they play an important role in atmospheric chemistry. In the troposphere, primary VOCs take part in chemical and/or photochemical reactions, thus contributing to the formation of ground-level ozone $\left(\mathrm{O}_{3}\right)$ (Logan et al., 1981; Liu et al., 1987; Chameides et al., 1992; Carter, 1994) and secondary organic aerosols (SOAs) (Tsigaridis and Kanakidou, 2003, and references therein; $\mathrm{Ng}$ et al., 2007). While some megacities face very poor air quality (such as Beijing; Gurjar, 2014) with pollutant concentrations way above recommended thresholds, European megacities experience stagnant pollution levels at the annual scale. However, pollution episodes related to high $\mathrm{O}_{3}$ and $\mathrm{PM}$ concentrations still regularly occur, leading to detrimental health consequences.

Epidemiological studies revealed that outdoor air pollution, mostly from $\mathrm{PM}_{2.5}$ and $\mathrm{O}_{3}$, could lead to 17800 premature deaths in France (with 3100 for the Paris megacity) in 2010 and projections for the future are even worse (3800 in 2025 and 4600 in 2050 for Paris) (Lelieved et al., 2015). Paris and its surroundings (also called the Île-de-France region) constitute the second largest European megacity with about 12 million inhabitants, representing $20 \%$ of the French national population distributed over only $2 \%$ of its territory (Eurostat, 2015). Although this region is surrounded by a rural belt, it is considered a large central urban area where a strong pollution signal can be detected. Deguillaume et al. (2008) have shown that the urban area of Paris was frequently associated with a VOC-sensitive chemical regime (also called an $\mathrm{NO}_{x}$-saturated regime, according to Sillman, 1999), for which VOC anthropogenic emission reductions are more effective in decreasing ozone levels than $\mathrm{NO}_{x}$ anthropogenic emission reductions. Obtaining accurate knowl- edge on VOC emissions and sources is consequently essential for $\mathrm{O}_{3}$ and SOA abatement measures.

Qualitative and quantitative assessments of VOC variability and sources have already been conducted within the Paris area during May-June 2007 (Gros et al., 2011; Gaimoz et al., 2011). This study concluded that road traffic activities (traffic exhaust and fuel evaporation) influenced the total VOC fingerprint, with a contribution of $\sim 39 \%$. This finding was considered as being in disagreement with the local emission inventory provided by the air quality monitoring network AIRPARIF (http://www.airparif.asso.fr), for which the main contribution was related to solvent usage (from industries and from residential sectors). However, this work was performed over a short period of time (only few weeks). Although it provided valuable information about ambient VOC emissions and sources during a specific period (spring), it did not show their seasonal variations over longer timescales. More resolved observations are therefore required to check the representativity of these first conclusions.

In this context, the EU-F7 MEGAPOLI (Megacities: Emissions, urban, regional and Global Atmospheric POLlution and climate effects, and Integrated tools for assessment and mitigation) (Butler, 2008) and the French PRIMEQUAL-FRANCIPOL research programs involving several (inter)national partners in the atmospheric chemistry community have been implemented. These MEGAPOLIFRANCIPOL projects partly consisted in documenting a large number of gaseous and particulate compounds and determining their concentration levels, variabilities, emission sources and geographical origins (local or imported) within the Paris urban area. These experiments therefore go beyond the scope of this paper and a full description of scientific studies conducted under the programme can be found in the special issue MEGAPOLI - Paris 2009/2010 campaign, available in the Atmospheric Chemistry and Physics (ACP) journal (e.g., Crippa et al., 2013; Skyllakou et al., 2014; AitHelal et al., 2014; Beekmann et al., 2015, and references therein).

Here, this work presents near-real-time measurements of VOCs performed at urban background sites in downtown Paris from 15 January to 22 November 2010. Its objectives are to (1) assess ambient levels of a VOC selection, (2) describe their temporal (seasonal and diurnal) variabilities, (3) identify their main emission sources from statistical modeling and (4) quantify and discuss their source contributions on yearly and seasonal bases.

In order to identify and apportion ambient VOC levels to their emission sources, the advanced multivariate receptor modeling technique positive matrix factorization (PMF) was applied. As no prior knowledge of the number or the chemical nature of source profiles is explicitly required (Paatero and Tapper, 1994), the identification of PMF source profile outputs must be made a posteriori. It usually relies on speciation profiles available in the literature. Within this study, near-field additional measurements (at source points inside 
a highway tunnel, at a fireplace and from a domestic gas flue) were performed to help strengthen this identification of VOC profiles derived from PMF simulations. This experimental approach is dedicated to provide a specific fingerprint of VOC sources related to road traffic, residential wood-burning activities and domestic natural gas consumption, respectively. The originality of this work stands in using these near-field speciation profiles to refine the identification of apportioned sources.

First, Sect. 2 will describe (i) sampling sites, (ii) analytical techniques conducted and (iii) two combined approaches for identifying and characterizing the main VOC emission sources. Then, Sect. 3 will investigate VOC levels and their seasonal and diurnal patterns from long-term ambient air measurements. An accurate identification of PMF factors to real physical sources will be proposed in the Sect. 3.4. Finally, yearly and seasonal contributions of each modeled source will be discussed in the Sect. 3.5 and compared to previous studies performed in Paris and widely in Europe in Sect. 3.6 and 3.7.

\section{Material and methods}

\subsection{Sampling sites' description}

As part of the European EU-F7 MEGAPOLI (Megacities: Emissions, urban, regional and Global Atmospheric POLlution and climate effects, and Integrated tools for assessment and mitigation (http://www.megapoli.info, 2007-2011)) program, a winter campaign involved measurements of a large amount of atmospheric compounds - with techniques including GC-FID and PTR-MS for VOCs - from 15 January to 16 February 2010 at the Laboratoire d'Hygiène de la Ville de Paris (LHVP) (Baklanov et al., 2010; Beekmann et al., 2015). Located in the southern part of Paris center (13th district $48^{\circ} 82^{\prime} \mathrm{N}, 02^{\circ} 35^{\prime} \mathrm{E}-15 \mathrm{~m}$ above ground level, a.g.1.), LHVP dominates a large public garden (called Parc de Choisy) at approximately $400 \mathrm{~m}$ from Place d'Italie (grouping a shopping center and main boulevards).

A second measurement campaign involving less instrumentation (only PTR-MS for VOCs) was conducted at the LHVP site from 24 March to 22 November 2010 (as part of the French PRIMEQUAL-FRANCIPOL program, Impact of long-range transport on particles and their gaseous precursors in Paris and its region (http://www.primequal.fr, 2010 2013)). At the same time, hydrocarbon measurements by GC-FID were carried out by the regional air quality monitoring network AIRPARIF at the Les Halles subway station $\left(48^{\circ} 51^{\prime} \mathrm{N}, 02^{\circ} 20^{\prime} \mathrm{E}-2.7 \mathrm{~m}\right.$ a.g.1.) located $2 \mathrm{~km}$ away from LHVP. The location of these two sampling sites is presented in Fig. 1.

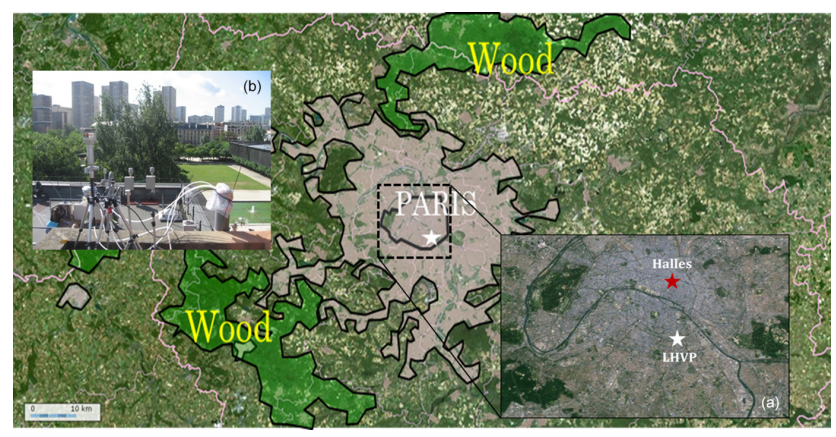

Figure 1. Maps of Paris and Île-de-France region. Panel (a) shows the location of the two main sampling sites in downtown Paris. The white and red stars locate the position of the LHVP laboratory and the AIRPARIF site, respectively. Panel (b) shows the terrace roof of LHVP.

\subsection{Representativeness of sampling sites}

Due to the low intensity of the surrounding activities, the LHVP and Les Halles sampling sites were considered as urban background stations by AIRPARIF and by previous scientific studies (Favez et al., 2007; Sciare et al., 2010; Gros et al., 2011). In accordance with the 2008/50/EC European Directive (Directive 2008/50/EC, 2008), this station typology is based on two main criteria: (1) the population density is at least 4000 inhabitants per square kilometer within a $1 \mathrm{~km}$ radius of the station and (2) no major traffic road is located within $300 \mathrm{~m}$.

This characterization of site typologies can be confirmed by studying the nitrogen monoxide (NO) to nitrogen dioxide $\left(\mathrm{NO}_{2}\right)$ ratio. $\mathrm{NO}$ is known to be a vehicle pollution indicator, whereas $\mathrm{NO}_{2}$ has an important secondary fraction. To consider a station as an urban background site, the ratio $R$ between annual average $\mathrm{NO}$ and $\mathrm{NO}_{2}$ concentrations $\left(\mathrm{NO} / \mathrm{NO}_{2}\right.$ ) should be less than $1.5 \mathrm{ppb} \mathrm{ppb}^{-1}$, as indicated in a report (Mathé, 2010) written at the national level for regulatory purposes.

We observed a very close $\mathrm{NO}: \mathrm{NO}_{2}$ ratio (expressed as $\mathrm{ppb} \mathrm{ppb}^{-1}$ ) between both sites in 2010: 0.40 (LHVP) vs. 0.38 (Les Halles). The same conclusion can be made for the years 2008 and $2009(0.45 \pm 0.01$ for LHVP and $0.48 \pm 0.01 \mathrm{ppb} \mathrm{ppb}^{-1}$ for Les Halles). With $\mathrm{NO}: \mathrm{NO}_{2}$ ratios very similar and less than 1.5 , this confirms that these two locations have the same site typology and can be considered as urban background stations.

To prove that it was valid to merge these two specific datasets from different locations, we opted for a comparison of PMF results derived from MEGAPOLI-FRANCIPOL (as performed in the present paper) and FRANCIPOL data files, respectively. PMF modeling simulations were performed using only the FRANCIPOL dataset. A good agreement was found for the majority of the emission sources. The graphs showing the comparison of PMF results between 
MEGAPOLI-FRANCIPOL and FRANCIPOL are reported in the Supplement Sect. S1.

\subsection{Experimental setup}

\subsubsection{VOC measurements using a proton transfer reaction - mass spectrometer (PTR-MS)}

Within the MEGAPOLI and FRANCIPOL projects, on-line high-sensitivity proton transfer reaction - mass spectrometers (PTR-MS, Ionicon Analytik GmbH, Innsbruck, Austria) were used for real-time $(\mathrm{O}) \mathrm{VOC}$ measurements. As this instrument has widely been described in recent reviews (Blake et al., 2009, and references therein), only a description of analytical conditions relating to ambient air observations is given here.

During these two intensive field experiments, a PTR-MS was installed in a small room located on the roof of the LHVP site (15 m a.g.l.). For the MEGAPOLI winter campaign, PTR-MS measurements performed by the Laboratoire de Chimie Physique (LCP, Marseille, France) have already been described in Dolgorouky et al. (2012). As those performed by the Laboratoire des Sciences du Climat et de l'Environnement (LSCE) during FRANCIPOL have not yet been described elsewhere, more technical details are presented below.

Air samples were drawn up through a Teflon line $(0.125 \mathrm{~cm}$ inner diameter) fitting into a Dekabon tube in order to protect it from light. A Teflon particle filter $(0.45 \mu \mathrm{m}$ pore diameter) was settled at the inlet to avoid aerosols and other fragments from entering the system. The PTRMS was operating at standard conditions: a drift tube held at $2.2 \mathrm{mbar}$ pressure, $60^{\circ} \mathrm{C}$ temperature with a drift field of $600 \mathrm{~V}$ to maintain an $E / N$ ratio of $\sim 130$ Townsend (Td) ( $E$ : electrical field strength $\left[\mathrm{V} \mathrm{cm}^{-1}\right] ; N$ : buffer gas number density [molecule $\mathrm{cm}^{-3}$ ]; $1 \mathrm{Td}=10^{-17} \mathrm{~V} \mathrm{~cm}^{2}$ ). First water cluster ions $\mathrm{H}_{3} \mathrm{O}^{+} \mathrm{H}_{2} \mathrm{O}$ (at $m / z$ 37.0) and $\mathrm{H}_{3} \mathrm{O}^{+} \mathrm{H}_{2} \mathrm{O} \mathrm{H}_{2} \mathrm{O}$ $(m / z 55.0)$ were also measured as well as $\mathrm{NO}^{+}$and $\mathrm{O}_{2}^{+}$ masses to indicate any leak into the system and assess the PTR-MS performances.

(O) VOC measurements performed in a full-scan mode were enabled to browse a large range of masses $(\mathrm{m} / \mathrm{z} 30.0$ $m / z 150.0)$. Eight protonated target masses were considered here: methanol $(m / z=33.0)$, acetonitrile $(m / z=42.0)$, acetaldehyde $(m / z=45.0)$, acetone $(m / z=59.0)$, methyl vinyl ketone $(\mathrm{MVK})+$ methacrolein $(\mathrm{MACR})+$ isoprene hydroxy hydroperoxides (ISOPOOHs) $(m / z=71.0$ ), benzene $(m / z=79.0)$, toluene $(m / z=93.0)$ and xylenes $(m+p-, o-)+\mathrm{C}_{8}$ aromatics $(m / z=107.0)$. With a dwell time of $5 \mathrm{~s}$ per mass, a mass spectrum was obtained every 2 to 10 min for MEGAPOLI and FRANCIPOL campaigns, respectively. Around $80 \%$ of PTR-MS data were validated. Missing data were partly due to background measurement periods and calibrations. The PTR-MS background for each mass was monitored by sampling zero air through a catalytic converter heated to $250^{\circ} \mathrm{C}$ to remove chemical species. Daily background values were averaged and subtracted from ambient air measurements.

In order to regularly ensure the analytical stability of the instrument, injections from a standard containing benzene $(5.7 \mathrm{ppbv} \pm 10 \%)$ and toluene $(4.1 \mathrm{ppbv} \pm 10 \%)$ were performed approximately once a month from March to November 2010. These measurements have shown that the analyzer stability remained stable during the year with variations within $\pm 10 \%$. In addition, two full calibrations were performed before and during the intensive field campaign with a gas calibration unit (GCU, Ionicon Analytik GmbH, Innsbruck, Austria). The standard gas mixture provided by Ionicon contained 17 VOCs at 1 ppmv. These calibration procedures consisted of injecting defined concentrations (in the range from 0 to $10 \mathrm{ppbv}$ ) of different chemicals (previously diluted with synthetic air) with a relative humidity at $50 \%$. Gas calibrations allowed to determine the repeatability of measurements, expressed here as a mean coefficient of variation. This coefficient was less than $5 \%$ for most of the masses. Slightly higher coefficients were observed for $\mathrm{m} / z 69.0$ (isoprene) and $\mathrm{m} / z 71.0$ (crotonaldehyde) with 5.6 and $5.2 \%$, respectively. Observed differences between both full calibration procedures were from $1.1 \%$ for methanol to $9.8 \%$ for toluene, thus illustrating good analyzer stability over time.

Detection limits (LoDs) were calculated as 3 times the standard deviation of the normalized background counts when measuring from the catalytically converted zero air. For the MEGAPOLI winter campaign, LoDs ranged from 0.020 to $0.317 \mu \mathrm{g} \mathrm{m}^{-3}(0.007-0.238 \mathrm{ppb})$, whereas they were estimated between 0.020 and $0.330 \mu \mathrm{g} \mathrm{m}^{-3}(0.007-0.248 \mathrm{ppb})$ during the FRANCIPOL intensive campaign. The analytical uncertainty on all data was estimated by taking into account errors on standard gas, calibrations, blanks, reproducibility/repeatability, linearity and relative humidity parameters. The measurement uncertainty was estimated at $\pm 20 \%$ in agreement with previous studies (Gros et al., 2011; Dolgorouky et al., 2012).

\subsubsection{NMHC on-line measurements by gas chromatography (GC)}

Two different automated gas chromatographs equipped with a flame ionization detector (GC-FID) were used in order to continuously measure light $\left(\mathrm{C}_{2}-\mathrm{C}_{6}\right)$ VOCs in ambient air. The AirmoVOC $\mathrm{C}_{2}-\mathrm{C}_{6}$ analyzer (Chromatotec, SaintAntoine, France), provided by LSCE, was installed near the PTR-MS at the LHVP site from January to February 2010 (e.g., MEGAPOLI period). An in-depth description of the analyzer, sampling setup and technical information (sampling flows, preconcentration, desorption-heating times, types of traps and columns, etc.) can be found in Gros et al. (2011). For each half-hour analysis, more than 20 VOCs were monitored. A certified standard gas mixture (NPL, National Phys- 
ical Laboratory, Teddington, Middlesex, UK) containing on average 4.00 ppbv of major $\mathrm{C}_{2}-\mathrm{C}_{9}$ NMHCs was used for calibration procedures. The injections of this standard allowed checking compound retention times, testing the repeatability of atmospheric measurements and calculating average response factors to calibrate all the measured ambient hydrocarbons. Detection limits were in the range of $0.013(n-$ hexane) $-0.060 \mu \mathrm{g} \mathrm{m}^{-3}$ (iso-/n-pentanes) (0.004-0.020 ppb). The analytical uncertainties on LSCE measurements were estimated from laboratory tests (i.e., memory effects, repeatability, accuracy of the gas standard) to be $\pm 15 \%$ (Gros et al., 2011).

From March to November 2010 (e.g., FRANCIPOL period), a GC-FID coupled to a thermo-desorption unit was in operation at the Les Halles subway station monitored by the regional air quality network AIRPARIF. Air samples were drawn up at $2.7 \mathrm{~m}$ a.g.1. A total of 29 hydrocarbons from $\mathrm{C}_{2}-$ $\mathrm{C}_{9}$ were measured during this experiment. A full calibration was performed once a month with a standard gas mixture containing only propane during $6 \mathrm{~h}$. As the FID response is proportional to the Effective Carbon Number (ECN) in the molecule, calibration coefficients were calculated for each compound and regularly checked so that they drifted no more than $\pm 5 \%$ (tolerance threshold). In addition, a zeroing was carried out every 6 months using a zero air bottle in order to detect any instability or problem with the GCFID system. LoDs were assessed at $0.024 \mu \mathrm{g} \mathrm{m}^{-3}$ for all the selected compounds, except for $n$-hexane $\left(0.013 \mu \mathrm{g} \mathrm{m}^{-3}\right)$ $(0.022-0.004 \mathrm{ppb})$. We were unable to perform a comprehensive calculation of uncertainties due a lack of sufficient information provided to us by AIRPARIF. Nevertheless, based on previous experimental tests, the NMHC measurements were provided by AIRPARIF with an accuracy of $\pm 15 \%$, which is the same level of uncertainty as we calculated for the LSCE GC-FID data.

\subsubsection{Additional data available}

Some ancillary pollutants and parameters were also measured and used as independent tracers with the aim of strengthening the identification of VOC emission sources derived from the receptor modeling.

Black carbon (BC) was measured using a sevenwavelength (370, 470, 520, 590, 660, 880 and $950 \mathrm{~nm})$ AE31 Aethalometer (Magee Scientific Corporation, Berkeley, CA, USA) with a time resolution of $5 \mathrm{~min}$. BC data were acquired by this instrument from 15 January to 10 September 2010. Raw data were corrected using the algorithm described in Weingartner et al. (2003) and Sciare et al. (2011). $\mathrm{BC}$ concentrations issued from fossil fuel and wood-burning $\left(\mathrm{BC}_{\mathrm{ff}}\right.$ and $\mathrm{BC}_{\mathrm{wb}}$, respectively) were assessed in accordance with their own absorption coefficients using the Aethalometer model described by Sandradewi et al. (2008).

Carbon monoxide (CO) measurements were performed using an analyzer based on infrared absorption (42i-TL instrument, ThermoFisher Scientific, Franklin, MA, USA) with a time resolution of $5 \mathrm{~min}$. Nitrogen monoxide and dioxide $\left(\mathrm{NO}, \mathrm{NO}_{2}\right)$ were measured by chemiluminescence using an AC31M analyzer (Environment SA, Poissy, France) and ozone $\left(\mathrm{O}_{3}\right)$ was monitored with an automatic ultraviolet absorption analyzer (41M, Environment SA, Poissy, France). $\mathrm{NO}, \mathrm{NO}_{2}$ and $\mathrm{O}_{3}$ measurements were provided with a 1 min time resolution by the local air quality network AIRPARIF. In addition, gas chromatography - mass spectrometry (GC-MS) measurements were performed to measure $\mathrm{C}_{3}-$ $\mathrm{C}_{7}$ OVOCs, including aldehydes, ketones, alcohols, ethers and esters during the MEGAPOLI winter campaign. This instrument has been described in detail by Roukos et al. (2009). As the measurement frequency was different for each analyzer, a common average time was defined to get all datasets on a similar time step of $1 \mathrm{~h}$.

Standard meteorological parameters (such as temperature, relative humidity as well as wind speed and direction) were provided by the French national meteorological service Météo-France from continuous measurements recorded at the Paris-Montsouris monitoring station (14th district $-48^{\circ} 49^{\prime} \mathrm{N}, 02^{\circ} 20^{\prime} \mathrm{E}$ ), located about $2 \mathrm{~km}$ away from the LHVP site.

In order to determine the air masses' origin, 5-day back trajectories were calculated every $3 \mathrm{~h}$ from the PC based version of the HYbrid Single-Particle Lagrangian Integrated Trajectory (HYSPLIT) model (Stein et al., 2015) with Global Data Assimilation System (GDAS) meteorological field data. Back trajectories were set to end at Paris coordinates $\left(49^{\circ} 02^{\prime} \mathrm{N}, 02^{\circ} 53^{\prime} \mathrm{E}\right)$ at $500 \mathrm{~m}$ a.g.1.

\subsection{Two combined approaches for characterizing VOC emission sources}

\subsubsection{Bilinear receptor modeling: PMF tool}

Developed about 20 years ago, PMF is an advanced multivariate factor analysis tool widely used to identify and quantify the main sources of atmospheric pollutants. Concerning VOCs, PMF studies have been conducted in urban (e.g., Brown et al., 2007 - Los Angeles, California, USA; Lanz et al., 2008 - Zürich, Switzerland; Morino et al., 2011 - Tokyo, Japan; Yurdakul et al., 2013 - Ankara, Turkey) and rural areas (e.g., Sauvage et al., 2009 - France; Lanz et al., 2009 - Jungfraujoch, Switzerland; Leuchner et al., 2015 - Hohenpeissenberg, Germany). For this current study, the PMF 5.0 software developed by the EPA (Environmental Protection Agency) was used in the robust mode from ambient air VOC measurements from January to November 2010. A more detailed description of this PMF analysis is given in Appendix A.

PMF mathematical theory was extensively described in Paatero and Tapper (1994). Briefly, this statistical method consists in decomposing an initial chemically speciated dataset into factor profiles and contributions. Equation (1) 
summarizes this principle in its matrix form:

$X=G F+E$,

where $X$ is the input chemical dataset matrix, $G$ is the source contribution matrix, $F$ is the source profiles matrix and $E$ is the so-called residual matrix.

The initial chemical database used for this statistical study contains a selection of 19 hydrocarbon species and masses divided into 10 compound families: alkanes (ethane, propane, iso-butane, $n$-butane, iso-pentane, $n$-pentane and $n$ hexane), alkenes (ethylene and propene), alkyne (acetylene), diene (isoprene), aromatics (benzene, toluene, xylenes plus $\mathrm{C}_{8}$ species), alcohol (methanol), nitrile (acetonitrile), aldehyde (acetaldehyde), ketone (acetone) and enones (methyl vinyl ketone, methacrolein and isoprene hydroxy hydroperoxides), which have been measured from 15 January to 22 November 2010 ( $n=6445$ with a $1 \mathrm{~h}$ time resolution). This combination of hydrocarbon species and masses is similar to that from Gaimoz et al. (2011) except for isobutene. Each missing data point was substituted with the median concentration of the corresponding species over all the measurements and associated with an uncertainty of 4 times the species-specific median, as suggested in Norris et al. (2014). The proportion of missing values ranges from $19 \%$ (especially for compounds measured by PTR-MS) to $41 \%$ (only for isoprene). This high percentage for isoprene can be mainly explained by analytical problems on GC-FID in July. Despite this limitation, it was decided to take into account this compound as isoprene is a key tracer related to biogenic emissions.

The uncertainty matrix was built upon the procedure described by Norris et al. (2014), adapted from Polissar et al. (1998). This matrix requires the method detection limit (MDL, here in $\mu \mathrm{g} \mathrm{m}^{-3}$ ) and the analytical uncertainty $(u$, here in percent) for each selected species. MDLs were calculated as $3 \sigma$ baseline noise and in some cases were homogenized to keep consistency in uncertainty calculations. Species MDLs were ranged from 0.013 to $0.060 \mu \mathrm{g} \mathrm{m}^{-3}$ (0.004$0.020 \mathrm{ppb}$ ) for NMHCs measured by GC-FID and from 0.020 to $0.330 \mu \mathrm{g} \mathrm{m}^{-3}(0.007-0.248 \mathrm{ppb})$ for VOCs measured by PTR-MS. Their analytical uncertainties were, respectively, estimated at 15 and $20 \%$ and kept constant over the experiments.

Single-species additional uncertainties were also calculated using an equation-based on the signal-to-noise $(S / N)$ ratio. As a first approach, Paatero and Hopke (2003) suggested categorizing a species as "bad" if the $S / N$ ratio was less than 0.2, "weak" if it was between 0.2 and 2 and "strong" if it was greater than 2. Bad variables are excluded from the dataset, weak variables get their uncertainties tripled while uncertainties of strong variables stay unchanged. Here, all species exhibited a $S / N$ ratio greater than 3 , except for isoprene which had a ratio of 1.7 due to its $41 \%$ missing values recorded. To address this lack of isoprene data, several empirical tests (e.g., simulating an averaged seasonal/diurnal cycle of isoprene or increasing the analytical uncertainty of raw data from 15 to $30 \%$ ) were conducted within PMF simulations with the aim of better modeling the variability of this compound. As a consequence of these tests, no significant improvement on the quality of modeling isoprene was observed. Finally, isoprene is still categorizing as strong here. In addition to isoprene, acetonitrile exhibited a $S / N$ ratio less than 3 ( $S / N$ ratio of 2.7). It was the only VOC to be defined as weak because it may be eventually contaminated with local emissions from laboratory exhausts (although visible spikes of acetonitrile were excluded from the initial dataset). Keeping in mind these limitations for isoprene and acetonitrile, it was decided to include these two compounds into the PMF model because they are considered relevant tracers for biogenic and wood-burning activities, respectively. $\Sigma$ VOC was defined as "total variable" and automatically categorized as weak to lower its influence in the final PMF results. No optional extra modeling uncertainty was applied here.

All the $Q$ values ( $Q_{\text {true }}, Q_{\text {robust }}, Q_{\text {expected }}$ ), scaled residuals, predicted vs. observed concentrations interpretation and the physical meaning of factor profiles were investigated to determine the optimum number of factors. Although some mathematical indicators pointed towards a five-factor solution, a source mixing solvent use activities, natural gas and background emissions was detected. In order to split each emission source individually, the six-factor solution was then investigated and chosen in terms of interpretability and fitting scores. More technical details are reported in Appendix A, Sect. A2.

PMF output uncertainties were estimated using two error estimation methods starting with DISP ( $\mathrm{d} Q$-controlled displacement of factor elements) and finally processing to BS (classical bootstrap). The DISP analysis results were considered validated: no error could be detected and no drop of $Q$ was observed. As no swap occurred, the six-factor PMF solution was considered sufficiently robust to be used. Bootstrapping was then carried out, executing 100 iterations, using a random seed, a block size of 874 samples and a minimum Pearson correlation coefficient ( $R$ value) of 0.6. All the modeled factors were well reproduced through this bootstrap technique over at least $88 \pm 2 \%$ of runs, hence highlighting their robustness. A low rotational ambiguity of the reconstructed factors was found by testing different degrees of rotations of the solution using the $F_{\text {peak }}$ parameter $\left(F_{\text {peak }}=0.1\right)$.

\subsubsection{Determination of source profiles from near-field observations}

As emphasized in Paatero and Tapper (1994), a PMF analysis does not require a priori knowledge on the chemical nature of factor profiles. To help strengthen the identification of VOC emission sources derived from this statistical tool, near-field additional measurements (at limited source points) were worthwhile. These in situ observations were performed 
close to specific local emission sources in real conditions as far as possible. They aim at providing chemical fingerprints (considered as reference speciation profiles) of three significant VOC sources representative within the Paris area: road traffic (i), residential wood-burning (ii) and domestic natural gas consumption (iii). The speciated profiles of these different anthropogenic sources and their representativity are given here. All the technical details of these experiments are reported in Sect. S2 in the Supplement.

\section{Highway tunnel experiment}

Road traffic was considered to be one of the most significant sources of primary hydrocarbons in many megacities (Seoul - Na, 2006; Los Angeles - Brown et al., 2007; Zürich - Lanz et al., 2008), including Paris (Gros et al., 2007, 2011; Gaimoz et al., 2011). The accurate characterization of the vehicle fleet footprint is therefore important. Consequently, near-field VOC measurements (within the PRIMEQUALPREQUALIF program) were conducted inside a highway tunnel located about $20 \mathrm{~km}$ southeast of inner Paris center in autumn 2012.

This first experiment has the advantage of supplying a realistic assessment of the average chemical composition of vehicular emissions, as these in situ measurements were performed under on-road real driving conditions. Most of VOCs emitted from road traffic are representative of local primary emissions (due to their relatively short lifetimes). Photochemical reactions leading to changes in the initial composition of the air and to the formation of secondary products can be considered of minor importance.

VOC levels during traffic jam periods (07:00-09:00 and 17:30-19:00 LT) were considered as the most representative values of vehicular emissions. In order to omit any local background, nighttime values (as suggested in Ammoura et al., 2014) were subtracted from the peak VOC concentrations. The mass contribution of 19 selected compounds was calculated and reported in Fig. 2. Each compound is expressed in terms of weight out of the weight $(w / w)$ of the total VOC (TVOC) mass. The two predominant species measured inside the highway tunnel were toluene $(19.4 \%$, $27.1 \mathrm{~g} \mathrm{~m}^{-3}$ (7.1 ppb) on average) and iso-pentane (18.6\%; $\left.26.0 \mu \mathrm{g} \mathrm{m}^{-3}(8.7 \mathrm{ppb})\right)$. The next most abundant VOCs were aromatics (benzene, $\mathrm{C}_{8}$ ) and oxygenated compounds (acetaldehyde and methanol) accounting for 5.0 to $10.0 \%$ (5$9 \mu \mathrm{g} \mathrm{m}^{-3}$ ) (1.1-4.6 ppb). In addition, significant contributions of light alkenes (ethylene, propene, acetylene; 3.3$4.5 \%$; 4.6-6.2 $\left.\mu \mathrm{g} \mathrm{m}^{-3}\right)(4.2-5.4 \mathrm{ppb})$ and alkanes (such as butanes, $n$-pentane, $n$-hexane, methyl alkanes) were also noticed. These observations were found to be consistent with the literature (Na, 2006; Araizaga et al., 2013, concerning NMHCs and Legreid et al., 2007, for OVOCs measurements) and more importantly with the study from Touaty and Bonsang (2000), for which iso-pentane, ethene, acetylene, propene and $n$-butane were considered as the major

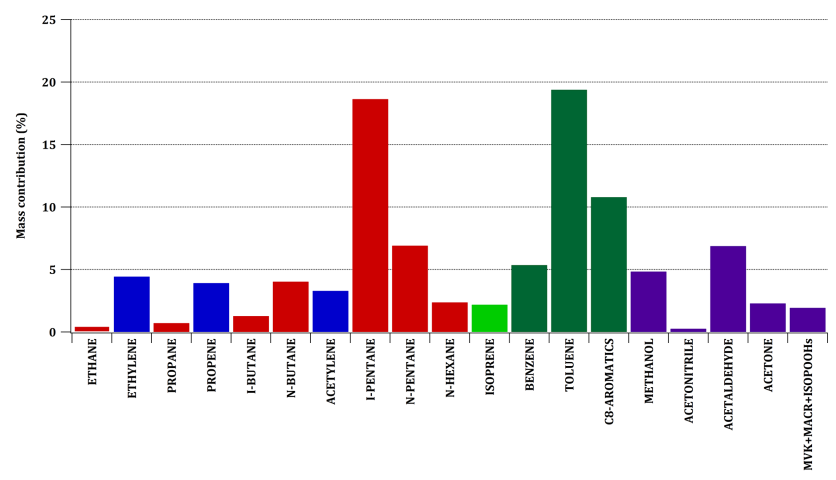

Figure 2. Average highway tunnel profile (in mass contribution, $\%$ ) assessed from traffic peaks concentrations and subtracted from nighttime values. Red, blue, light/dark green and purple bars correspond to alkanes, alkenes-alkynes, isoprene/aromatics and oxygenated species, respectively.

aliphatic compounds observed in the same highway tunnel in August 1996 (aromatics and OVOCs were not measured during this study).

\section{Fireplace experiment}

Residential wood-burning activities have been shown to be a significant source of $(\mathrm{O})$ VOCs to local indoor and outdoor air pollution during winter months in urban areas (Evtyugina et al., 2014). Currently, only a few studies about the characterization of VOCs from wood-burning have been conducted in Europe (Gustafson et al., 2007; Gaeggeler et al., 2008). After being subject to lively debates within the Île-de-France region, an in-depth investigation of this source would therefore appear necessary to better understand its emission specificities and its potential impacts on atmospheric chemistry.

In order to complete the information on wood-burning activities, VOC measurements (within the CORTEACHAMPROBOIS program) were performed at a fireplace facility located $\sim 70 \mathrm{~km}$ northeast of the inner Paris center in March 2013. On-line (PTR-MS) and off-line (sampling flasks analyzed later on at the laboratory with a GC-FID) measurements were performed. These in situ observations represent a more qualitative (predominant species identification) than quantitative approach as the resulting speciation profile is based on a limited number of data. As illustrated in Fig. 3, 19 VOC species could be detected. $\mathrm{C}_{2}$ hydrocarbons (ethylene, acetylene), $\mathrm{C}_{6}-\mathrm{C}_{8}$ aromatics (benzene, xylenes) and oxygenated species (methanol, acetaldehyde and acetone) can be considered as predominant compounds from domestic wood-burning. This finding is still consistent with intensive field studies of wood-burning performed in Europe (Barrefors and Petersson, 1995; Gaeggeler et al., 2008; Evtyugina et al., 2014; Nalin et al., 2016). 


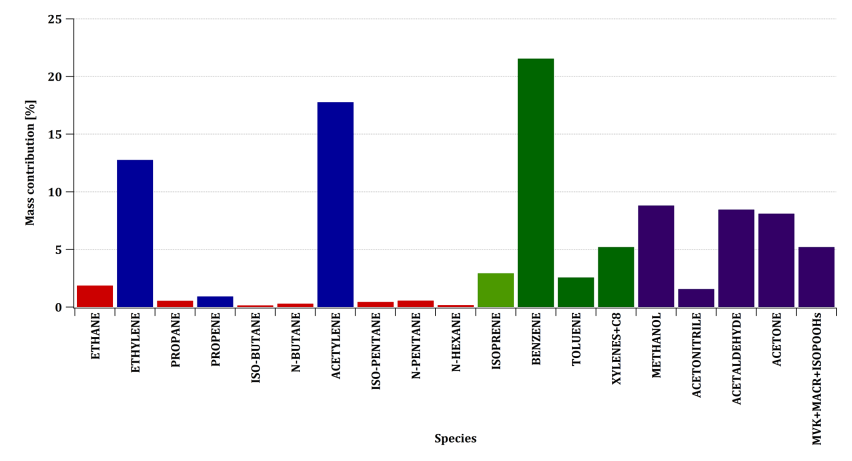

Figure 3. Average VOC fingerprint (in mass contribution, \%) from domestic biomass burning obtained during the fireplace experiment. Red, blue, light/dark green and purple bars correspond to alkanes, alkenes-alkynes, isoprene/aromatics and oxygenated species, respectively.

\section{Natural gas experiment}

Natural gas is predominately composed of methane $\left(\mathrm{CH}_{4}\right)$ accounting for at least $80 \%$ of the total chemical composition. It is also a mixture of other pollutants including lightweight VOCs and lower paraffins (approximately $10 \%$ by volume).

In a first approach to determine the speciation profile from natural gas used in Paris, near-field samplings were performed from a domestic gas flue using three stainless-steel flasks, which have been analyzed by GC-FID at the laboratory. Main results (Fig. 4) show a large dominance of alkanes, such as ethane $(\sim 80 \%)$, propane $(\sim 11 \%)$ and heavier hydrocarbons (like butanes, pentanes) ranging from 4.5 to $0.4 \%$. Ethane and propane therefore appear as a significant profile signature of natural gas leakages (Passant, 2002).

\section{Results and discussions}

\subsection{Meteorological conditions and air-mass origins}

Meteorological parameters (e.g., temperature, relative humidity, rainfall, sun exposure, boundary layer height, wind speed and direction) are known to be key factors governing seasonal and diurnal variations of air pollutant levels.

Air temperatures observed during the campaign were comparable to standard values determined by the French national meteorological service Météo-France (2015, available at http://meteofrance.com), however with an uncommon cold wintertime (Bressi et al., 2013 - Fig. S1a). Temperatures recorded in January and February 2010 were, respectively, between -2 and $-3.5^{\circ} \mathrm{C}$ below normal values (see Sect. S3 in the Supplement). Extreme unusual cold-air outbreaks and a few snow flurries affected the Paris region, thus explaining higher temperature anomalies during that period. Levels of hours of sunshine and rainfall were globally consis-

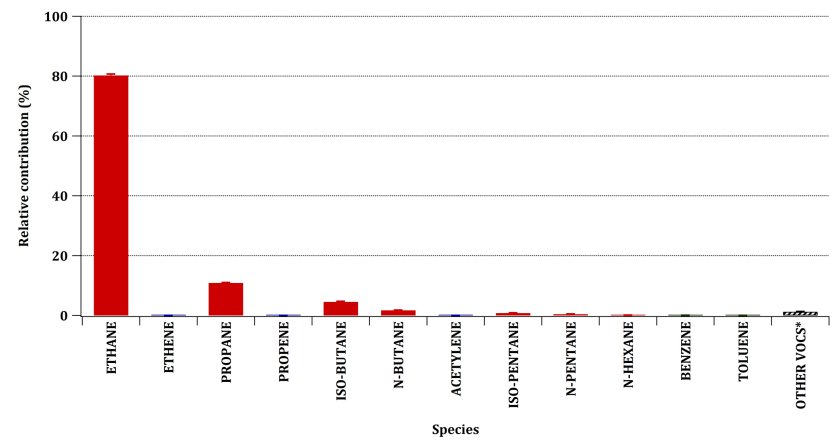

Figure 4. Average chemical composition of natural gas used in Paris. *Other VOCs include heavier alkanes (e.g., cyclopentane/hexane, dimethyl butanes) and butenes in lower proportions. Whiskers correspond to error bars $(1 \sigma)$.

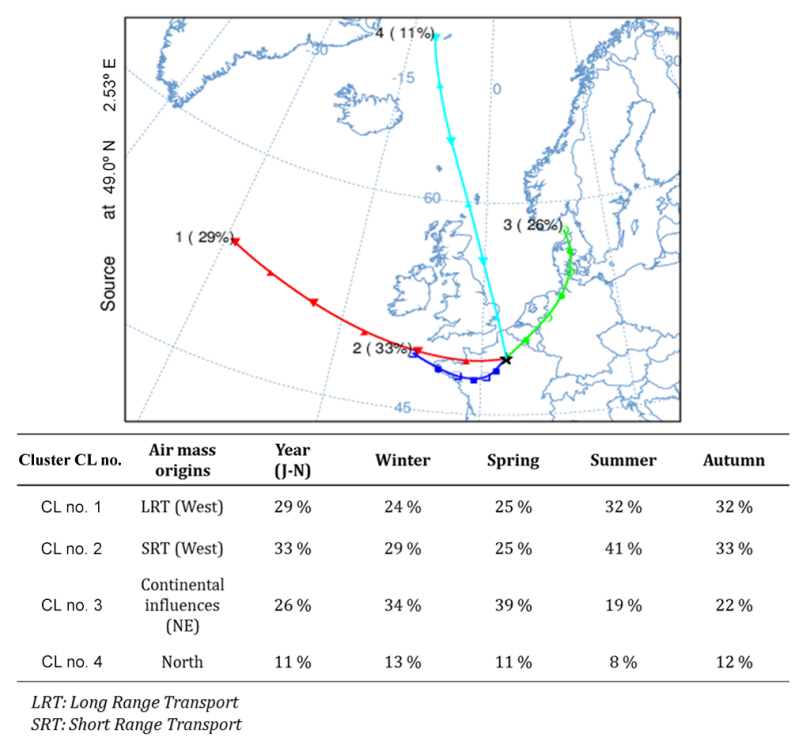

Figure 5. Average trajectories obtained after clustering analysis and the relative proportion of clusters $(\%)$ over the year and per season.

tent with standard values, however with some discrepancies in winter/autumn and spring, respectively (Fig. S3). In addition, atmospheric boundary layers showed seasonal changes with mean heights up to $\sim 800 \mathrm{~m}$ in winter and up to $1600 \mathrm{~m}$ in spring and summer occurring during the afternoon (see Sect. S4 in the Supplement). These average seasonal heights are expected to play a key role in pollutant dispersion and consequently impact ambient VOC concentrations.

For the year 2010, Paris was mainly influenced by air masses coming from the west $(62 \%)$ and usually associated with clean marine air influences from the Atlantic Ocean (see Fig. 5). They are typically representative of local and regional pollution conditions, as already observed in Gros et al. (2011), Gaimoz et al. (2011), Dolgorouky et al. (2012) and Petit et al. (2015). To a lesser extent, Paris can be affected by northeast air masses (26\%) originating from east- 
Table 1. Statistical summaries $\left(\mu \mathrm{g} \mathrm{m}^{-3}\right.$ ) of selected VOC concentrations measured at urban background sites. Statistics were calculated from hourly mean data, initially obtained every $30 \mathrm{~min}$ (ethane > isoprene) and every 5 to $10 \mathrm{~min}$ (for aromatics and OVOCs). These measurements were undertaken from 15 January to 22 November 2010 ( $\sim 10$ months). A conversion factor is provided here to convert VOC concentrations $\left(\mu \mathrm{g} \mathrm{m}^{-3}\right)$ into $(\mathrm{ppb})$ mixing ratios.

\begin{tabular}{|c|c|c|c|c|c|c|c|c|c|}
\hline & Species & Conversion factor & Minimum & 25 th percentile & Median & Mean & 75th percentile & Maximum & $\sigma$ \\
\hline \multirow[t]{7}{*}{ Alkanes } & Ethane & 1.25 & 0.83 & 3.07 & 4.14 & 4.56 & 5.42 & 26.31 & 2.26 \\
\hline & Propane & 1.83 & 0.23 & 1.63 & 2.44 & 2.78 & 3.45 & 25.64 & 1.80 \\
\hline & Iso-butane & 2.42 & 0.23 & 1.12 & 1.58 & 1.96 & 2.30 & 23.52 & 1.51 \\
\hline & $N$-butane & 2.42 & 0.40 & 1.88 & 2.69 & 3.35 & 3.93 & 56.10 & 2.88 \\
\hline & Iso-pentane & 3.00 & 0.25 & 1.25 & 1.82 & 2.24 & 2.68 & 25.81 & 1.65 \\
\hline & $N$-pentane & 3.00 & 0.10 & 0.58 & 0.85 & 1.04 & 1.28 & 12.04 & 0.76 \\
\hline & $N$-hexane & 3.58 & 0.06 & 0.27 & 0.40 & 0.49 & 0.59 & 4.25 & 0.34 \\
\hline \multirow[t]{2}{*}{ Alkenes } & Ethylene & 1.17 & 0.04 & 0.81 & 1.25 & 1.55 & 1.92 & 14.04 & 1.14 \\
\hline & Propene & 1.75 & 0.09 & 0.37 & 0.53 & 0.64 & 0.78 & 5.93 & 0.44 \\
\hline Alkyne & Acetylene & 1.08 & 0.04 & 0.29 & 0.48 & 0.68 & 0.81 & 7.39 & 0.64 \\
\hline Diene & Isoprene & 2.83 & 0.08 & 0.13 & 0.19 & 0.26 & 0.31 & 1.74 & 0.22 \\
\hline \multirow[t]{3}{*}{ Aromatics } & Benzene & 3.25 & 0.04 & 0.62 & 0.89 & 1.05 & 1.26 & 7.60 & 0.66 \\
\hline & Toluene & 3.83 & 0.12 & 1.79 & 2.46 & 3.29 & 3.68 & 34.56 & 2.86 \\
\hline & Xylenes $+\mathrm{C}_{8}$ & 4.42 & 0.26 & 1.58 & 2.19 & 2.76 & 3.25 & 21.84 & 1.97 \\
\hline Alcohol & Methanol & 1.33 & 0.86 & 3.66 & 4.83 & 5.89 & 6.83 & 39.29 & 3.89 \\
\hline Nitrile & Acetonitrile & 1.71 & 0.10 & 0.30 & 0.40 & 0.71 & 0.67 & 31.87 & 1.09 \\
\hline Aldehyde & Acetaldehyde & 1.83 & 0.54 & 2.02 & 2.71 & 3.17 & 3.71 & 15.04 & 1.83 \\
\hline Ketone & Acetone & 2.42 & 0.73 & 3.05 & 4.33 & 4.87 & 5.79 & 22.24 & 2.64 \\
\hline Enone & MVK + MACR & 2.92 & 0.05 & 0.30 & 0.48 & 0.65 & 0.77 & 6.27 & 0.59 \\
\hline
\end{tabular}

ern France, the Benelux area, northern Germany and indicative of continental imports of long-lived pollutants (Gaimoz et al., 2011). Air masses coming from the west are generally observed in summer and autumn (32-41\%), whereas northeast air masses are found to be significant in winter (34\%) and most frequently in spring (ca. $40 \%$ ), due to the stagnation of an anticyclone surrounding the British Isles (monthly weather report for Paris and its surroundings during April 2010, Météo-France) during that period.

\subsection{VOC concentration levels in ambient air}

The main results of descriptive statistics for all the measured VOCs (from both GC-FID and PTR-MS instruments) on the whole sample set were summarized in Table 1 . The average composition of VOCs was mainly characterized by oxygenated species $\left(0.7-5.9 \mu \mathrm{g} \mathrm{m}^{-3}(0.4-4.4 \mathrm{ppb}) ; 36.5 \%\right.$ of the TVOC mass), alkanes $\left(0.5-4.6 \mu \mathrm{g} \mathrm{m}^{-3}(0.1-3.7 \mathrm{ppb})\right.$; $39.1 \%$ ) followed by aromatics $\left(1.1-3.3 \mu \mathrm{g} \mathrm{m}^{-3} ; 16.9 \%\right.$ $(0.3-0.9 \mathrm{ppb}))$ and to a lesser extent by alkenes, alkynes and dienes $\left(0.3-1.6 \mu \mathrm{g} \mathrm{m}^{-3}(0.1-1.3 \mathrm{ppb}) ; 7.5 \%\right)$. Both alkanes and OVOCs significantly contribute up to $75 \%$ of the TVOC concentrations. With ethane $\left(10.9 \%, 4.6 \mu \mathrm{g} \mathrm{m}^{-3}\right.$ (3.7 ppb) on average) being the main alkane, methanol (14.0\%, $\left.5.9 \mu \mathrm{g} \mathrm{m}^{-3}(4.4 \mathrm{ppb})\right)$ and acetone $\left(11.6 \%, 4.9 \mu \mathrm{g} \mathrm{m}^{-3}\right.$ $(2.0 \mathrm{ppb}))$ are considered to be the two major oxygenated compounds measured in this study. This conclusion is in agreement with previous VOC measurements performed in downtown Paris in 2007 (Gros et al., 2011).

The comparison between these average ambient levels and VOC measurements reported in the literature for different urban areas is restricted here to PTR-MS data as they constitute the most original dataset of this study. Most atmospheric studies were indeed conducted in urban metropolitan areas by investigating only NMHC measurements.

Table 2 summarizes PTR-MS data collected during the intensive experiment together with average VOC levels reported in ppb from other cities around the world. For the Paris megacity, a significant decrease in VOC concentrations was observed between spring 2007 and spring 2010 (from $-53.8 \%$ for xylenes and $\mathrm{C}_{8}$ aromatics to $-25 \%$ for benzene and MVK + MACR + ISOPOOHs), except for methanol and acetaldehyde $(+11.8 \%,+35.7 \%$, respectively). These differences in aromatic concentration levels are consistent with decreasing downward trends of NMHC recorded during springtime in Paris (Waked et al., 2016). We note that the study of Waked et al. (2016) on VOC trends in Paris only concerns NMHC and not oxygenated species. As these OVOCs are significantly impacted by biogenic and secondary sources, it is not surprising to observe a different variation between 2007 and 2010 . 
Table 2. Comparison of mean concentrations of selected VOCs (measured by PTR-MS) with ambient levels observed in the literature from different urban atmospheres. All average values are reported in parts per billion.

\begin{tabular}{|c|c|c|c|c|c|c|c|c|}
\hline $\begin{array}{l}\text { VOCs measured } \\
\text { by PTR-MS }(\mathrm{m} / \mathrm{z})\end{array}$ & $\begin{array}{r}\operatorname{Paris}^{\mathrm{a}}(P .) \\
\text { Jan-Nov } \\
(\text { spring }) \\
2010\end{array}$ & $\begin{array}{l}\text { Parisb } \\
\text { spring } \\
2007\end{array}$ & $\begin{array}{r}\text { Barcelona }{ }^{\mathrm{c}, 1} \\
\text { winter } \\
2009\end{array}$ & $\begin{array}{r}\text { London }^{\mathrm{d}}(P .) \\
\text { Oct } \\
2006(2010)\end{array}$ & $\begin{array}{r}\operatorname{Mohali}^{\mathrm{e}}(P .) \\
\text { May } \\
2012(2010)\end{array}$ & $\begin{array}{r}\operatorname{Mexico} \operatorname{City}^{\mathrm{f}}(P .) \\
\text { Mar } \\
2006(2010)\end{array}$ & $\begin{array}{r}\text { Beijing }^{g}(P .) \\
\text { Aug } \\
2005(2010)\end{array}$ & $\begin{array}{r}\operatorname{Houston}^{\mathrm{h}}(P .) \\
\text { Aug-Sep } \\
2000(2010)\end{array}$ \\
\hline Methanol (33.0) & $4.5(6.6)$ & 5.9 & NA & NA (3.3) & $38(5.3)$ & NA (1.6) & $11.7(2.8)$ & $10.8(3.9)$ \\
\hline Acetonitrile (42.0) & $0.7(1.2)$ & 0.4 & $0.2-0.5$ & $0.3(0.2)$ & $1.4(0.5)$ & $0.3-1.4(0.2)$ & NA $(0.3)$ & $0.5(0.5)$ \\
\hline Acetaldehyde (45.0) & $1.8(1.9)$ & 1.4 & $0.8-1.7$ & $3.6(1.5)$ & $6.7(1.7)$ & $3.0-12.0(1.1)$ & $3.6(1.1)$ & $3.4(1.5)$ \\
\hline Acetone (59.0) & $2.1(2.5)$ & 3.0 & $1.1-1.6$ & $1.6(2.2)$ & $5.9(2.1)$ & NA $(1.7)$ & $4.4(1.6)$ & $4.0(2.1)$ \\
\hline $\begin{array}{l}\text { MVK + MACR } \\
+ \text { ISOPOOHs (71.0) }\end{array}$ & $0.2(0.2)$ & 0.3 & $0.07-0.12$ & NA $(0.2)$ & NA $(0.1)$ & $\mathrm{NA}(0.1)$ & $0.3-0.6(0.2)$ & $0.8(0.2)$ \\
\hline Benzene (79.0) & $0.3(0.3)$ & 0.4 & $0.2-0.6$ & $0.1(0.4)$ & $1.7(0.3)$ & NA $(0.3)$ & NA $(0.2)$ & $0.6(0.3)$ \\
\hline Toluene (93.0) & $0.9(0.9)$ & 1.4 & $0.8-2.7$ & $1.9(0.9)$ & $2.7(0.8)$ & $3.0-28.0(0.6)$ & $1.0-4.0(0.5)$ & $0.8(0.9)$ \\
\hline Xylenes $+\mathrm{C}_{8}(107.0)$ & $0.6(0.6)$ & 1.3 & $0.9-3.4$ & $0.2(0.7)$ & $2.0(0.7)$ & NA $(0.4)$ & NA $(0.4)$ & $0.6(0.6)$ \\
\hline
\end{tabular}

Among selected species, benzene (as a carcinogenic agent) is one of the few regulated VOCs. According to the directive 2000/69/EC (2000), the annual mean benzene concentration in ambient air should not exceed $5 \mu \mathrm{g} \mathrm{m}^{-3}(1.5 \mathrm{ppb})$. Background levels of benzene were relatively stable in recent years, with an annual average concentration of $1.1 \mu \mathrm{g} \mathrm{m}^{-3}$ (0.3 ppb) (Airparif, 2015).

Average VOC concentrations were also calculated in line with sampling periods of the other European and global studies over different years (see Table 2). In this study, measured VOC levels were in the range of those found within some European cities (Barcelona and London - from 0.1 to 2.1 ppb concentration differences). However, average VOC levels observed in Paris were significantly lower than those measured in Houston (USA - from 0.1 to $6.9 \mathrm{ppb}$ concentration differences) and more particularly in Beijing (China - from 2.5 to $8.9 \mathrm{ppb}$ ), in Mexico City (Mexico - from 0.1 to $27.4 \mathrm{ppb}$ ) and in Mohali (India - from 0.9 to $32.7 \mathrm{ppb}$ ).

\subsection{Seasonal and diurnal variations}

The variability in VOC concentration levels is controlled by a combination of factors including source strengths (e.g., emissions), dispersion and dilution processes as well as photochemical reaction rates with $\mathrm{OH}$ radicals and other oxidants (Filella and Peñuelas, 2006). Variations of selected trace gases (nitrogen / carbon monoxide, NO / CO - Fig. 6) and VOCs illustrating contrasting emission sources and atmospheric lifetimes were analyzed at different timescales. As (O)VOCs measured by PTR-MS constitute the most original data of this study (and represent $\sim 37 \%$ of the TVOC mass); a discussion on their variations (Fig. 7) and their respective sources is given here. For information, an overview of seasonal and diurnal profiles of lighter hydrocarbons $\left(\mathrm{C}_{2}-\mathrm{C}_{6}\right)$ measured by GC-FID is reported in Sect. S6 in the Supplement.
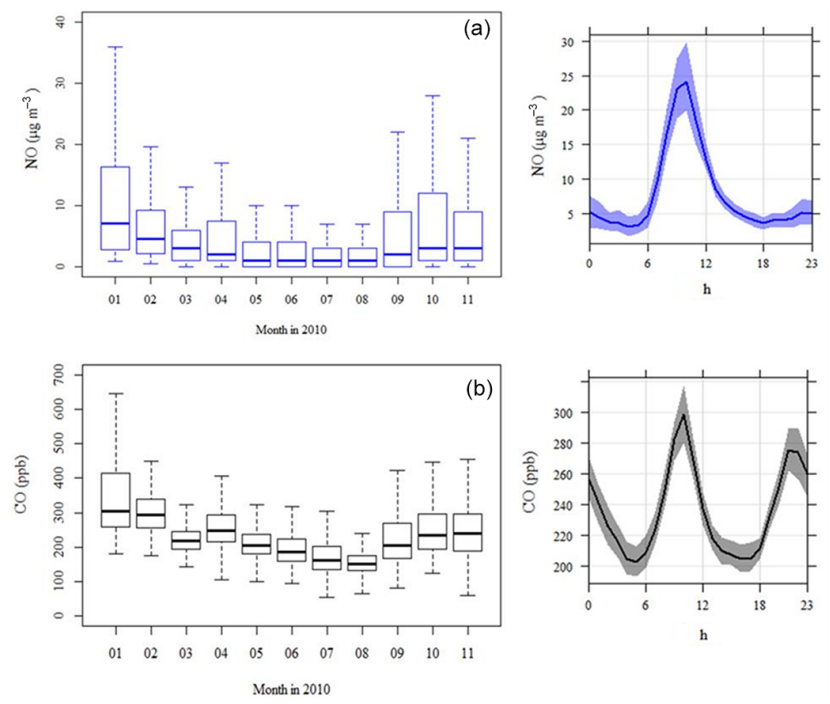

Figure 6. Left: monthly box and whisker plots of $\mathrm{NO}$ (a) and $\mathrm{CO}$ (b) expressed in $\mu \mathrm{g} \mathrm{m}^{-3}$ and $\mathrm{ppb}$, respectively. Solid lines represent the median concentration and the box shows the interquartile range (IQR). The bottom and top of the box depict the 25th (the first quartile) and the 75th (the third quartile) percentile. The ends of the whiskers correspond to the lowest and highest data still within 1.5 times the IQR of Q1 and Q3, respectively. Right: diurnal variations of NO and $\mathrm{CO}$ averaged over the whole sampling period. Time is given as local time. Lines correspond to hourly means and shaded areas indicate the $95 \%$ confidence intervals of the mean.

Known as combustion tracers (traffic / wood-burning), nitrogen monoxide (NO) and carbon monoxide (CO) exhibit higher median concentrations during winter and in late autumn, while lower concentrations appear in summer (Fig. 6a, b). These low levels can be explained by greater photochemical reaction rates (linked to higher solar radiation) combined with a stronger vertical atmospheric mix- 

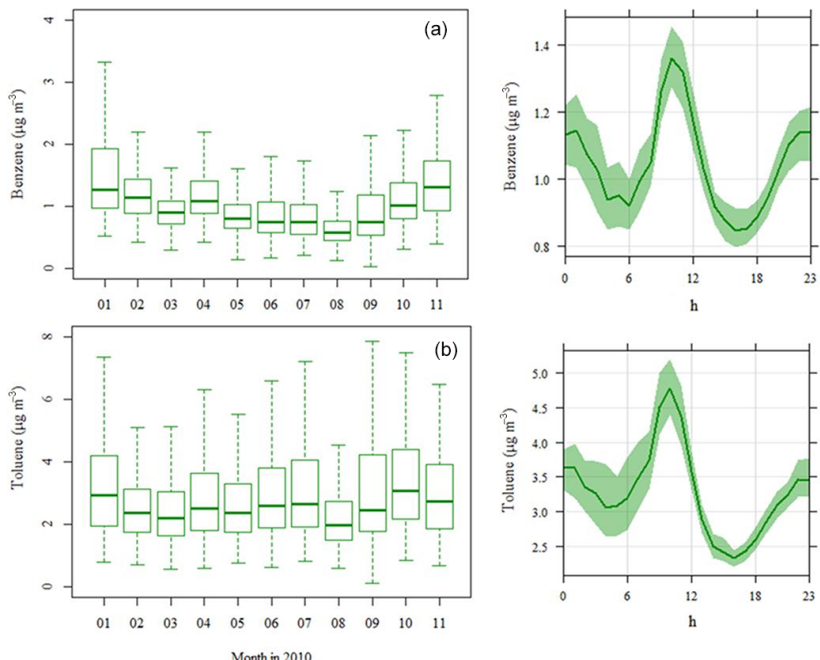

Figure 7.

ing compared to the other seasons. Another explanation of this variability is the increase in $\mathrm{NO}$ and $\mathrm{CO}$ emissions due to home heating fuels consumed in winter. NO concentrations are significantly enhanced between 06:00 and 12:00 LT (with the maximum around 09:00 LT). Contrary to NO, the diurnal pattern of $\mathrm{CO}$ is characterized by a double wave profile with an initial peak at 07:00-10:00 LT (maximum at 09:00 LT) and a second one at the end of the afternoon between 16:00 and 21:00 LT. These increases typically correspond to morning and evening rush-hour traffic periods, as previously observed in Ammoura et al. (2014). The evening peak is smaller in magnitude than the morning one partly due to a higher planetary boundary layer (PBL) height in the afternoon (leading to dispersion and dilution processes) and to more disperse traffic periods. After 21:00 LT, CO levels stay quite high (240-260 ppb) due to several factors: ongoing emissions (traffic and wood-burning activities), lower photochemical reactions and atmospheric dynamics (the shallower boundary layer leads to more accumulation of $\mathrm{CO}$ (and other co-emitted species)). The evening event is not observed for $\mathrm{NO}$ as during this time ozone $\left(\mathrm{O}_{3}\right)$ presents its highest concentrations, leading to the titration of NO.

Good correlations between $\mathrm{CO}$ and some alkanes (iso-/ $n$ pentane, $n$-hexane), alkenes (ethylene, propene), acetylene and aromatics (benzene, toluene and xylenes plus $\mathrm{C}_{8}$ ) were found when considering a Pearson's correlation coefficient $r$ greater than 0.6. All these compounds follow a similar seasonal and diurnal pattern, indicating that they share some or almost all common sources related to anthropogenic combustion processes (e.g., road traffic and/or wood-burning). These observations are in agreement with the conclusions from Gros et al. (2011) and Gaimoz et al. (2011).

With atmospheric lifetimes from a few hours to several days, oxygenated species (OVOCs) are emitted from primary sources, mainly of biogenic origins, and significant

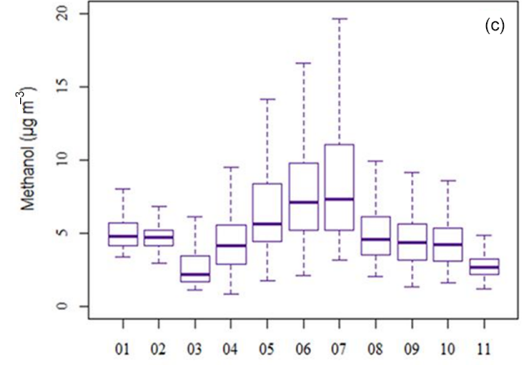

Month in 2010
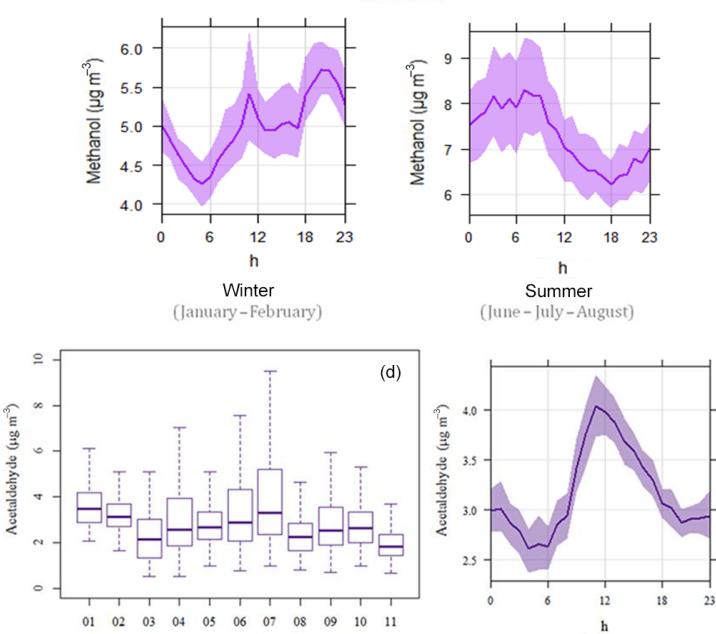

Moath in 2010
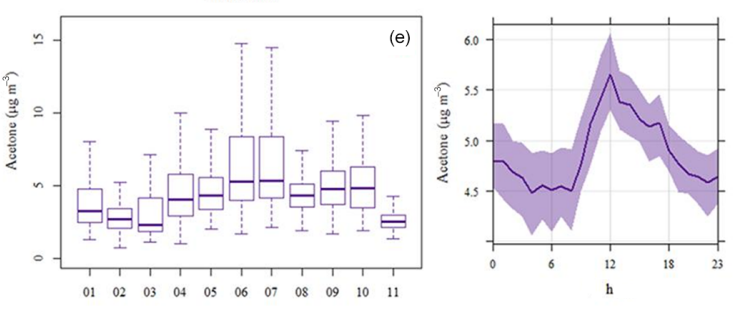

Month in 2010
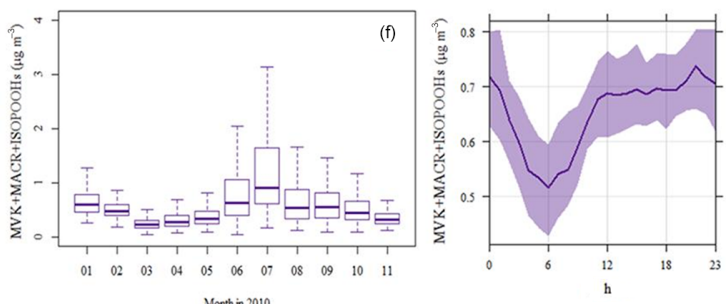

Figure 7. Left: monthly box and whisker plots of benzene (a), toluene (b), methanol (c), acetaldehyde (d), acetone (e) and MVK + MACR + ISOPOOHs (f) expressed as $\mu \mathrm{g} \mathrm{m}^{-3}$. Solid lines represent the median concentration and the box shows the IQR. The bottom and top of the box depict the 25th (the first quartile) and the 75th (the third quartile) percentile. The ends of the whiskers correspond to the lowest and highest data still within 1.5 times the IQR of Q1 and Q3, respectively. Right: diurnal variations of $(\mathrm{O}) \mathrm{VOCs}$ averaged over the whole sampling period. Time is given as local time. Lines correspond to hourly means and shaded areas indicate the $95 \%$ confidence intervals of the mean. 
secondary sources related to the oxidation of hydrocarbons. High concentration levels of OVOCs (for instance, methanol) and $\mathrm{CO}$ were observed during winter months (the season with coldest temperatures and where wood-burning-related activities can play an important role). The low height of the PBL is also a relevant factor to consider as it can lead to the stagnation and the accumulation of VOC species into the troposphere during that season. In addition, significant OVOC levels were observed from April to September. In springtime, elevated baseline levels were measured when the Paris region was mostly influenced by northeast influences (see Fig. 5), suggesting that they partly depended on continental imported and already processed air masses. Biogenic emissions indeed contributed to high OVOC concentrations during this season and in summer.

Methanol is usually released into the atmosphere by vegetation and man-made activities contributing to a relatively high background levels during most of the year. This compound displays a specific diurnal pattern depending on the season and atmospheric dynamics (see Sect. S4 in the Supplement). In winter, methanol shows a double wave profile with two peaks at 10:00-11:00 and 19:00-20:00 LT (see Fig. 7c, bottom left), suggesting the influence of anthropogenic activities (e.g., road traffic, wood-burning sources). A slight delay (1-2h) is observed for methanol in comparison to other primary species (for instance, aromatics). In summer, methanol is characterized by high concentrations during night hours (00:00-06:00 LT), followed by a significant decrease until the early afternoon and another increase from 18:00 LT to midnight (Fig. 7c, bottom right). This nighttime maximum of methanol has already been observed in urban environments, however, with no clear explanation (Solomon et al., 2005). This diurnal cycle can possibly be interpreted as the accumulation of species concentrations during the night from a local source under a shallow inversion layer, which is decreasing when the PBL is increasing (as dilution and dispersion processes are occurring). However, the corresponding nighttime source has not been yet identified.

With a relatively short lifetime $(\sim 9 \mathrm{~h})$, acetaldehyde shows a diurnal cycle fairly comparable to acetone (Fig. 7d, e). Lower concentrations were observed during the night and from 18:00LT. Average levels increase from sunrise to a maximum at noon and slightly decrease in the afternoon. For these two OVOC species, the reduction of concentrations does not occur in the same way. From 12:0018:00 LT, average acetaldehyde concentrations are linearly decreasing $\left(\sim 1.0 \mu \mathrm{g} \mathrm{m}^{-3}\right.$ or $\left.0.5 \mathrm{ppb}\right)$ while mean acetone levels show a slower decline rate $\left(\sim 0.5 \mu \mathrm{g} \mathrm{m}^{-3}\right.$ or $\left.0.25 \mathrm{ppb}\right)$ with a tiny raise at 17:00 LT. This finding depends on their emission sources and strengths (e.g., biogenic, solvent use), but also on their respective photochemical reaction rates $\left(1.5 \times 10^{-11} \mathrm{~cm}^{3}\right.$ molecule ${ }^{-1} \mathrm{~s}^{-1}$ for acetaldehyde and $1.8 \times 10^{-13} \mathrm{~cm}^{3}$ molecule ${ }^{-1} \mathrm{~s}^{-1}$ for acetone) (Atkinson et al., 2006). As acetone has a relatively long atmospheric lifetime ( $\sim 68$ days), concentration levels are often more homogeneous.

Finally, methyl vinyl ketone, methacrolein and isoprene hydroxy hydroperoxides (MVK + MACR + ISOPOOHs), three secondary products of isoprene photo-oxidation (as good indicators of biogenic activities), exhibit high levels in the late afternoon due to the oxidation of daytime isoprene. The formation of these compounds mostly occurs in summer, but also in winter (Fig. 7f). This fact could eventually be related to anthropogenic activities such as wood-burning (see Sect. 2.4.2, Fig. 3).

\subsection{Source apportionment}

\subsubsection{Motor vehicle exhaust factor}

The speciation profile of Factor 1 (see Fig. 8a) exhibits high contributions of alkanes, such as pentanes (iso- $/ n-$ ) and $n$-hexane with on average $\sim 50 \%$ of their variabilities explained by this factor. Aromatic compounds (toluene, xylenes plus $\mathrm{C}_{8}$, benzene; $\sim 35 \%$ ) and light alkenes (ethylene, propene), which are considered as typical combustion products, are also the predominant species in this factor.

To evaluate the relevance of this factor, a comparison between speciated profiles from tunnel measurements (Fig. 2) and PMF simulations was done and is reported in Fig. 9. Traffic profiles are in general coherent and consistent amongst themselves, thus allowing to label this factor as a motor vehicle exhaust source. Indeed, a good agreement is observed between these two profiles for the major species such as iso-/n-pentane, toluene, ethylene and propene. Instead, significant differences in mass contributions for ethane (almost a factor of 10), acetylene (considered as a key combustion compound emitted from traffic not identified in the PMF profile), isoprene (represented by evaporative sources) and oxygenated species were found. These differences can potentially be explained by several reasons. Firstly, the proportion of VOC emitted from traffic may be different depending upon the types of vehicles/engines/fuels (Montero et al., 2010). VOC emissions can also be dependent on the use of vehicles (age, maintenance), driving situations and thermal conditions (hot soak). Secondly, the vehicle fleet composition is different in the center of Paris and in the highway tunnel. Although the proportion of passengers cars and light duty vehicles (LDVs) accounts for $60-90 \%$ of the total composition of the fleet in circulation in both cases, the share of two-wheelers and heavy goods vehicles can be different. Indeed, heavy vehicles are subject to traffic limitations prohibiting their entry in Paris, whereas they are allowed in the highway tunnel (5\%). The proportion of two-wheelers is significant in Paris (10-20\%) (Airparif, 2013) while they represent less than $2 \%$ of the total vehicles in the tunnel. Finally, PMF artefacts cannot be excluded. We suppose that the contribution of ethane in the motor vehicle exhaust factor is overestimated (same as the wood-burning factor) at the expense 


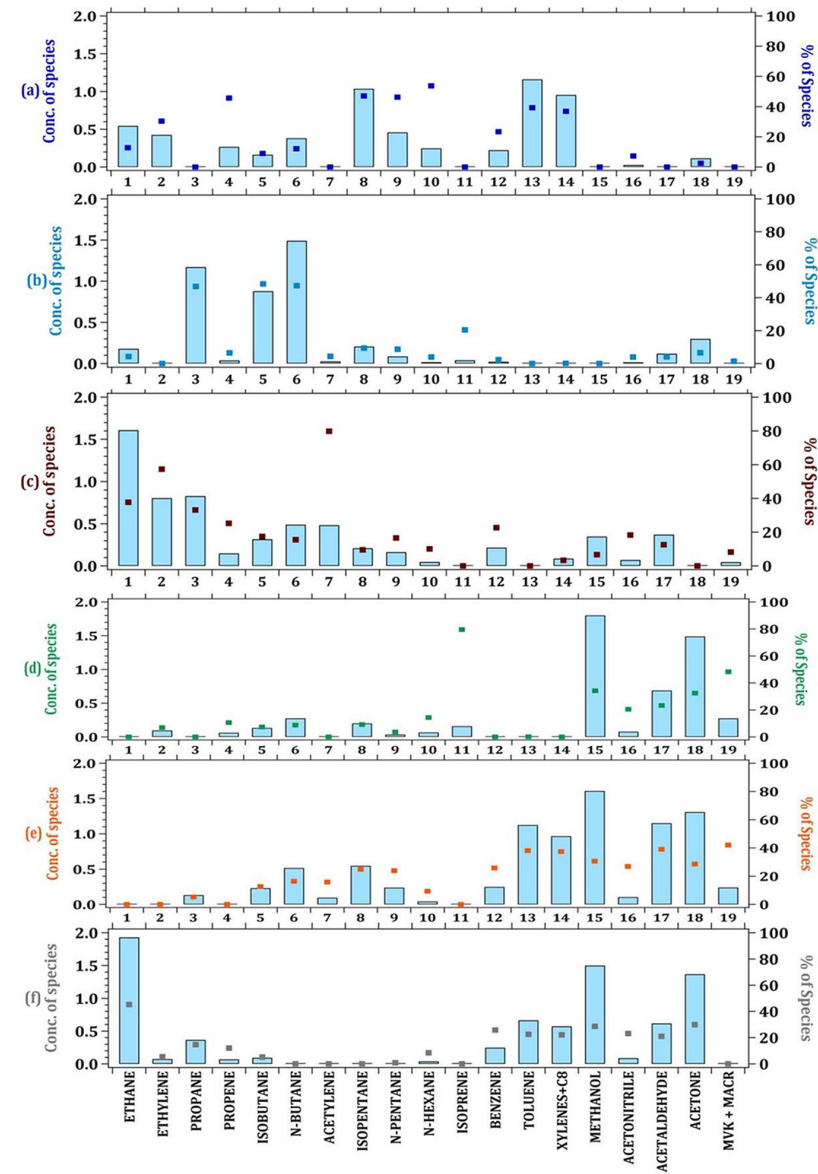

Figure 8. Source composition profiles of the six-factor PMF solution. The concentrations $\left(\mu \mathrm{g} \mathrm{m}^{-3}\right)$ and the percent of each species apportioned to the factor are displayed as a pale blue bar and a color box, respectively. (a) F1 - motor vehicle exhaust; (b) F2 - evaporative sources; (c) F3 - wood-burning; (d) F4 - biogenic; (e) F5 solvent use; (f) F6 - natural gas and background.

of the mixed natural gas and background source (for which ethane contributions seem to be underestimated).

Factor 1 displays fair correlations with nitrogen monoxide/dioxide $\left(\mathrm{NO} / \mathrm{NO}_{2}\right)$, carbon monoxide $(\mathrm{CO})$ and black carbon (from its fossil fuel fraction), which are known to be relevant vehicle exhaust markers $(0.53<r<0.64)$. The average contribution of this factor is rather stable throughout the year $\left(5.8 \mu \mathrm{g} \mathrm{m}^{-3}\right.$; see Fig. 10, panel 1 and Sect. S7 in the Supplement). A smaller contribution is found during winter $\left(3.2 \mu \mathrm{g} \mathrm{m}^{-3}\right)$, whereas the highest emissions from motor vehicle exhaust occur in autumn $\left(8.6 \mu \mathrm{g} \mathrm{m}^{-3}\right.$ on average) with a contribution of up to $10.1 \mu \mathrm{g} \mathrm{m}^{-3}$ in September. This seasonal cycle has already been observed and described in Bressi et al. (2014) for the road traffic source of fine aerosols in Paris. The diurnal variation of this source is characterized by a double wave profile with an initial increase at 07:00-10:00 LT and a second increase at the end of the afternoon between 16:00 and 19:00 LT. These in-

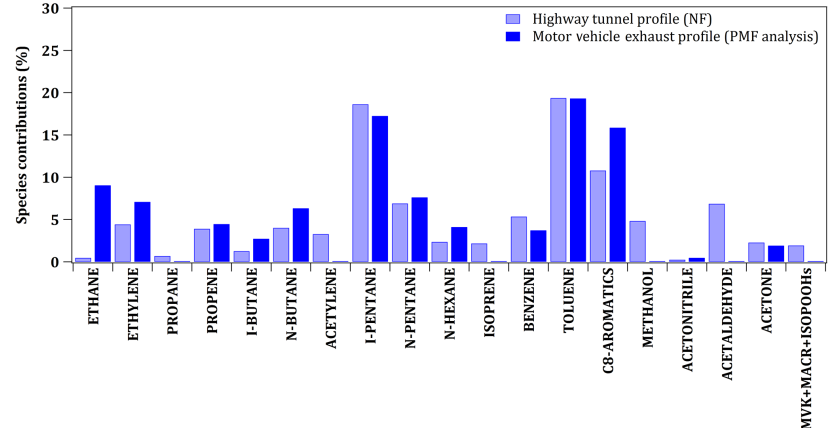

Figure 9. Comparison of speciated profiles issued from the highway tunnel experiment and PMF simulations (F1 - motor vehicle exhaust). The species contributions are expressed in percent. $\mathrm{NF}=$ near-field.

creases correspond to morning and evening rush-hour traffic periods. After 21:00 LT, the absolute contributions of this factor stay quite high $\left(7.0-8.0 \mu \mathrm{g} \mathrm{m}^{-3}\right)$ due to several factors: ongoing emissions (until midnight), lower photochemical reactions and atmospheric dynamics (the shallower boundary layer leads to more accumulation of pollutants at night). Lower contributions are generally displayed during late mornings/early afternoons and at night. This reduction in factor contributions could be mainly explained by dilution and $\mathrm{OH}$ oxidation processes of more reactive species, which are not being balanced by additional vehicular emissions. This pronounced cycle has already been reported in previous studies (Gaimoz et al., 2011, and references therein). The temporal source strength variation is usually much more pronounced during weekdays than the weekend.

\subsubsection{Evaporative sources factor}

The profile of Factor 2 (see Fig. 8b) exhibits a high contribution from propane and iso- $/ n$-butanes, with more than $47 \%$ of their variabilities explained by this factor. It was already identified by Gaimoz et al. (2011) and is used here as reference profile from gasoline evaporation emissions (including storage, extraction and distribution of gasoline or liquid petroleum gas (LPG)). The generic term "evaporative sources" is here used to take into account these types of evaporative emissions. Factor 2 also includes a significant proportion of isoprene $(20 \%)$. This finding is still consistent with the conclusions of Borbon et al. (2001), which have shown that traffic activities emit a small amount of isoprene. In the same way, oxygenated compounds (acetaldehyde (4\%), acetone $(6.6 \%)$ ) were found in fugitive evaporative emissions in agreement with what was observed during the highway tunnel experiment (see Fig. 2).

Among independent tracers used, only NO displays a fair agreement with this factor $(r=0.35)$. A correlation between $\mathrm{F} 2$ and $\mathrm{F} 1$ can also be noted $(r=0.36)$, thus indicating that these two factors are related to a common source (e.g., road 

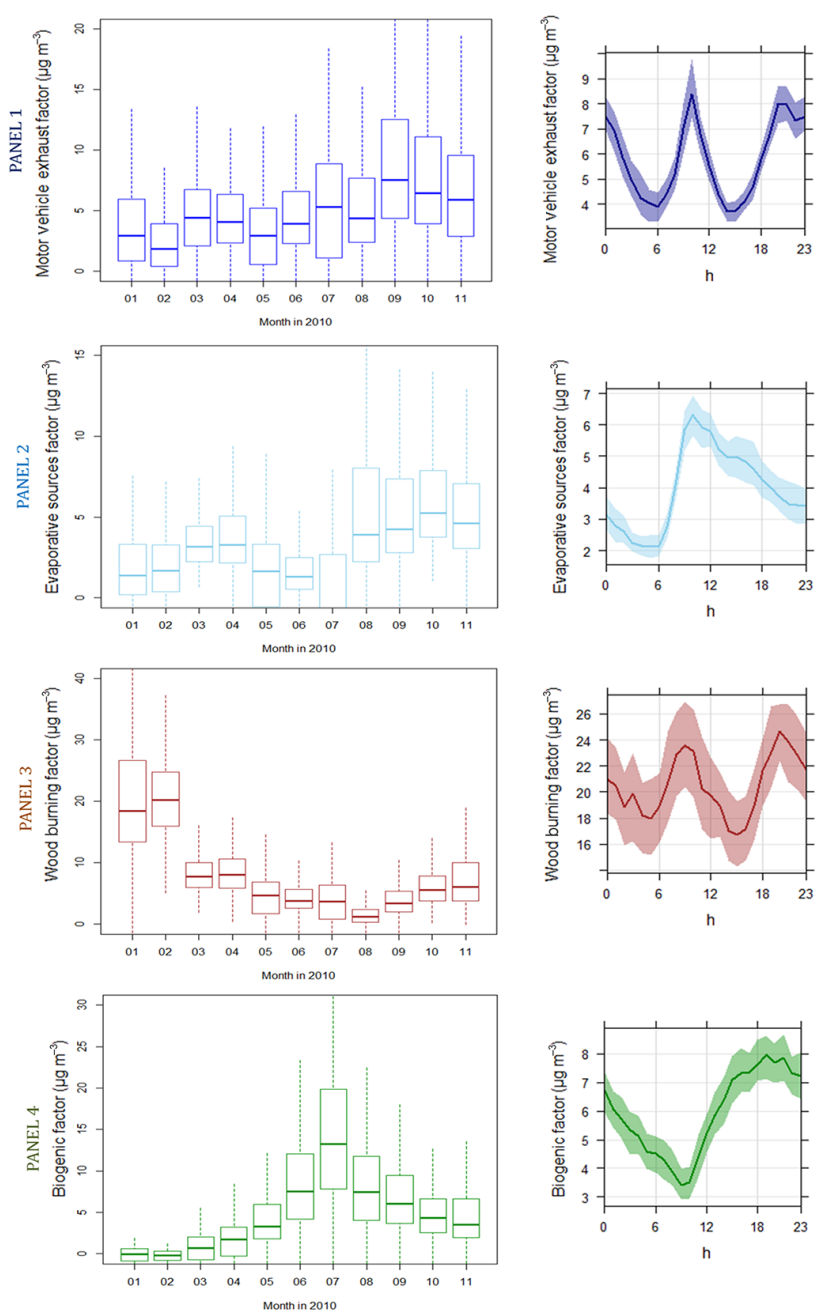

Figure 10.

traffic). This source is in the range of $\sim 3.9 \mu \mathrm{g} \mathrm{m}^{-3}$ over the whole studied period (see Fig. 10, panel 2). The annual trend of F2 seems to be consistent with the motor vehicle exhaust factor (F1), even though its monthly change remains ambiguous. Indeed, lower evaporative contributions are recorded both in winter and in early summer with minimum average contributions in June and July $\left(1.7 \mu \mathrm{g} \mathrm{m}^{-3}\right)$. This finding was already identified by Frachon (2009). However, this value in June is somewhat puzzling as road traffic emissions are usually significant $\left(4.9 \mu \mathrm{g} \mathrm{m}^{-3}\right)$. In July, propane and butanes (iso-/n-) values were missing due to analytical problems on the operating GC-FID. Consequently, these compounds were simulated by the PMF model (e.g., missing values were virtually substituted by median values) which may underestimate the contribution of this factor during this specific period of time. However, high contributions of this source occur in August $\left(6.6 \mu \mathrm{g} \mathrm{m}^{-3}\right)$. Although exhaust emissions are not particularly important, this observation could be eventually explained by gasoline storage and distribution sources,
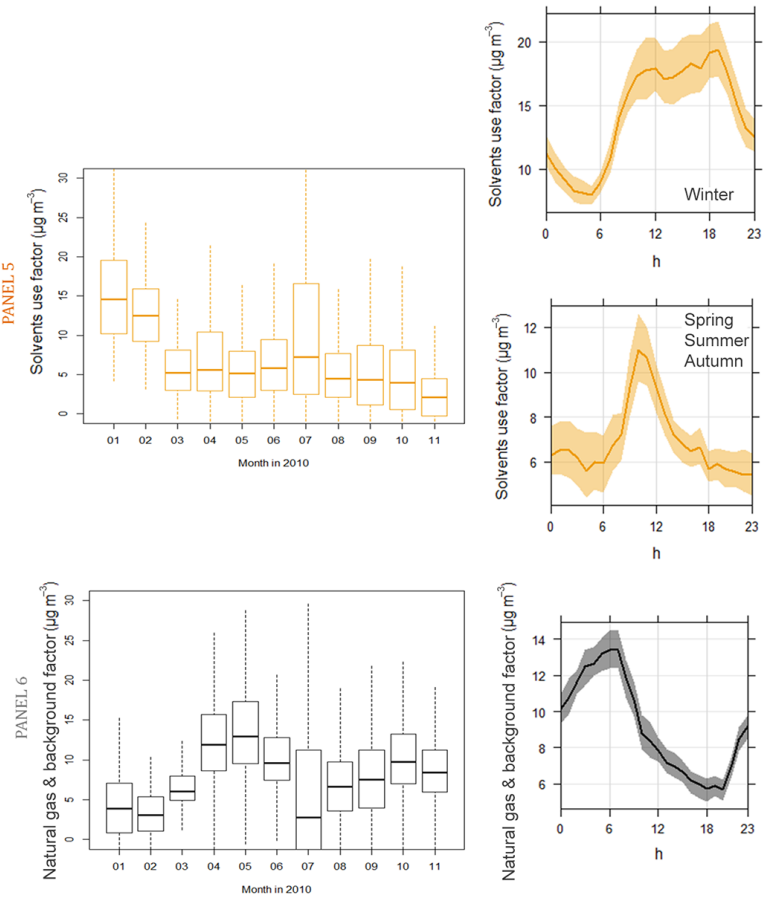

Figure 10. Left: monthly box and whisker plots of modeled sources from the six-factor solution. Concentration levels are expressed in $\mu \mathrm{g} \mathrm{m}^{-3}$. Solid lines represent the median concentrations and the box shows the IQR. The bottom and top of the box depict the 25th (the first quartile) and the 75th (the third quartile) percentile. The ends of the whiskers correspond to the lowest and highest data still within 1.5 times the IQR of Q1 and Q3, respectively. Right: diurnal variations of the resolved PMF factors. Time is given in local time. Lines correspond to hourly means and shaded areas indicate the $95 \%$ confidence intervals of the mean.

which may have increased with higher temperatures during that month. Maxima temperatures have generally been in the range of 16 to $32^{\circ} \mathrm{C}$. The source contribution is on average higher in autumn $\left(6.1 \mu \mathrm{g} \mathrm{m}^{-3}\right)$ with a contribution of up to $6.3 \mu \mathrm{g} \mathrm{m} \mathrm{m}^{-3}$ in October.

The diurnal variation of this factor contribution is characterized by a nighttime minimum, an increase from 07:00 to 10:00 LT (consistent with the motor vehicle exhaust factor, F1) and a much slower decrease in emissions during the afternoon than those observed for the vehicle combustion profile. This second factor therefore represents the emissions of less reactive species (OVOCs, propane, butanes), for which concentrations cannot be expected to be consumed photochemically in short transport times. The temporal source strength variation is less pronounced on weekends than weekdays, which is typical of mobile source activity patterns.

According to the Copert IV (European Environment Agency, EEA) program for the calculation of air pollutant emissions from road transport, gasoline evaporation emissions can be explained by the evaporation of VOCs due to temperature, vehicle refueling, running losses, diurnal and 
hot soak reactions (when a hot engine is switched off). It was speculated that hot engines would emit more in the morning than in the evening, considering typical conditions of active inhabitants going to and from their workplace. Fugitive gasoline emissions from the loading of tank trucks, transportation and unloading from tank trucks at service stations and distributions depots can also be likely sources of this factor. In summary, this source depends on several parameters (related to road traffic conditions, the vehicle fleet composition, economic activities and meteorological observations), which can make the interpretation of its seasonal variability difficult.

\subsubsection{Wood-burning factor}

In Paris, domestic wood-burning represents a non-negligible part (about $5 \%$ ) of the energy consumption by fuel used for home heating (Airparif, 2011). The chemical profile of this source (Factor 3), shown in Fig. 8c, is mainly dominated by acetylene with approximately $80 \%$ of its variability explained by this factor. It also includes ethylene ( $57.4 \%$ ), benzene $(22.7 \%)$ and oxygenated compounds, such as acetonitrile, acetaldehyde and methanol (with 18.3, 12.6 and $8.2 \%$, respectively). Acetonitrile is a hydrocarbon commonly used as a marker of biomass burning (Holzinger et al., 1999). All these chemical species typically reflect an anthropogenic source related to wood combustion processes (Lanz et al., 2008; Leuchner et al., 2015) in agreement with the fireplace emission profile (see Sect. 2.4.2, Fig. 3). No full comparison between both speciation profiles was possible as the fireplace profile was based on a limited number of data. With this mind, only a qualitative approach allowed to identify predominant species emitted from this source and confirm the term "wood-burning" assigned to this factor.

Biomass burning emissions are well correlated with black carbon originating from residential wood-burning $\left(\mathrm{BC}_{\mathrm{wb}}\right)$ and carbon monoxide, a long-lived compound especially emitted from combustion reactions $(0.6<r<0.7)$. In addition, they co-vary well with naphthalene $(\mathrm{m} / \mathrm{z} 129.0$ measured by PTR-MS), a known polyaromatic hydrocarbon emitted from combustion processes (industry, tailpipe emissions) including wood-burning (Purvis and McCrillis, 2000). As expected, wood-burning contributions display a distinct cycle with a winter maximum $\left(20.5 \mathrm{\mu g} \mathrm{m}^{-3}\right.$ on average $)$ and a summer minimum $\left(3.3 \mu \mathrm{g} \mathrm{m}^{-3}\right)$. Average contributions of this factor are rather stable in both spring and fall (6.9 and $5.9 \mu \mathrm{g} \mathrm{m}^{-3}$, respectively).

Wood-burning emissions linked to home/building heating are obviously highly dependent on meteorological conditions and particularly on cold temperatures. A clear negative relationship between the wood-burning factor and temperature is found $(r=-0.56)$. The diurnal variation of this source exhibits a double wave profile. Average contributions increase from sunrise to a maximum in midmorning and decrease until 16:00-17:00 LT. At the end of the day, a second increase is observed with another maximum contribution at 19:00-
21:00 LT. This diel cycle can be explained by domestic behaviors. An important finding is that the diurnal pattern of this source is fairly comparable to that of the motor vehicle exhaust factor. However, the wood-burning factor does not display any distinct weekly variation. High contributions are observed all week (without any distinction between weekdays and weekends) compared to motor exhausts, for which vehicular emissions are less pronounced on weekends than weekdays. In addition, it exhibits poor correlations with NO, $\mathrm{NO}_{2}$ and $\mathrm{BC}_{\mathrm{ff}}(r=0.30,0.29$ and 0.19 , respectively), thus indicating that the wood-burning factor is completely independent of the motor vehicle exhaust source.

\subsubsection{Biogenic factor}

The profile of Factor 4 (see Fig. 8d) exhibits a high contribution from isoprene, a known chemical marker of biogenic emissions, with more than $79 \%$ of its variability explained by this factor. In addition, this factor profile includes isoprene's oxidation products (methyl vinyl ketone (MVK), methacrolein (MACR) and isoprene hydroxy hydroperoxides (ISOPOOHs)), methanol and acetone. These oxygenated compounds have a large contribution from biogenic emissions (Kesselmeier and Staudt, 1999; Guenther, 2002). It also accounts a significant contribution of some light alkenes (e.g., ethylene and propene), which can be evenly emitted by plants (Goldstein et al., 1996). Consequently, this factor F4 is termed "biogenic factor". Amounts of light alkanes (butanes, iso-pentane, $n$-hexane) and acetonitrile were also found in this profile and could be attributed to a mixing with other temperature-related sources or artefacts from the PMF model (Leuchner et al., 2015).

Biogenic emissions are directly related to solar radiation (Steiner and Goldstein, 2007) and ambient temperature $(r>0.7)$. For that reason, the highest biogenic factor contributions occur in summer $\left(10.5 \mu \mathrm{g} \mathrm{m}^{-3}\right.$ on average $)$ with a contribution of up to $14.3 \mu_{\mathrm{g} \mathrm{m}}^{-3}$ in July. Daily mean contributions gradually increase from 09:00 LT. A slight delay is observed in comparison with diurnal temperature/solar radiations variations (for which values increase from sunrise at 06:00 LT). We assume that chemistry affects this factor as it takes part in the formation of secondary species (MVK + MACR + ISOPOOHs, for instance) from the oxidation of primarily emitted compounds (isoprene, OVOC). Diurnal contributions reach their maximum at the end of the day (at 19:00 LT). Highest nighttime contributions of this source can be explained by the presence of oxygenated species (long-lived compounds already present in the atmosphere and/or secondarily formed from the oxidation of isoprene) in the profile combined with lower photochemical reactions and atmospheric dynamics (a low PBL height) at night. 


\subsubsection{Solvent use factor}

The profile of Factor 5, shown in Fig. 8e, is associated with a large contribution of selected OVOCs (acetaldehyde, methanol and acetone) with on average $\sim 33 \%$ of their variabilities explained by this factor. Significant contributions from aromatic compounds (toluene, xylenes plus $\mathrm{C}_{8}$ and benzene) and some alkanes (pentanes, butanes, propane and $n$ hexane) are also observed. Toluene, in addition to road traffic, is a good marker for solvents originating from an industrial source (Buzcu and Fraser, 2006). Benzene, due to its toxic and carcinogen nature, was regulated in recent years and was strongly limited in solvent formulations. Current standards establish limits in benzene concentrations at $0.1 \%$ in cleaning products. However, PMF results point out the presence of benzene in this factor, suggesting that this compound might potentially still be in use by some manufacturers. Finally, the presence of these aforementioned species illustrates that this profile could be linked to industrial emissions, although a mixing of different sources cannot be excluded.

This factor co-varies well with ethanol, butan-2-one (also called methyl ethyl ketone - MEK), isopropyl alcohol or even ethyl acetate $(0.68>r>0.52$, respectively) - four organic compounds that were measured by GC-MS during the MEGAPOLI campaign (January-February 2010). These species are often used as solvents, diluents or cleaning fluids in industrial processes (Zheng et al., 2013). Some manufactories can consume fossil fuels for their activities, which may explain the fairly good correlation between this factor and black carbon originating from fossil fuels $\left(\mathrm{BC}_{\mathrm{ff}}, r=0.50\right)$. Indeed, these fossil fuels could be used by industries as diverse as paints, paintings inks and lacquers (Tsai et al., 2001; Cornelissen and Gustafsson, 2004).

The highest contribution of this factor is observed during winter $\left(14.2 \mu \mathrm{g} \mathrm{m}^{-3}\right)$ with a contribution of up to $15.5 \mu \mathrm{g} \mathrm{m}^{-3}$ in January. In winter, factor contributions increase at 06:00 and reach their maximum between 11:00 and 19:00 LT (15-20 $\left.\mathrm{\mu g} \mathrm{m}^{-3}\right)$ before a long and gradual decline in the evening (see Fig. 10, panel 5 - top right). Higher contributions in winter can be explained by lower photochemical reactions (combined with weaker $\mathrm{OH}$ concentrations/UV radiations) and atmospheric dynamics. Indeed, a shallower PBL (and consequently, less intense vertical dynamics) leads to more accumulation of pollutants and thus to higher source contributions. The daily wintertime variability of this source is in agreement with the diel cycle of independent tracers (ethanol, butan-2-one).

Reconstructed contributions associated with this factor are also significant in summer $\left(12.6 \mu \mathrm{g} \mathrm{m}^{-3}\right.$ in July), which could be mainly explained by the evaporation of solvent inks, paints and other applications during that month due to higher temperatures. In spring/summer/autumn, factor contributions also increase at sunrise, but reach their maximum between 08:00 and 10:00 LT (typical of anthropogenic activ- ities). They progressively decrease during the afternoon (see Fig. 10, panel 5 - bottom right). This gradual decline (not earlier observed in winter) is influenced by greater photochemical reactions and more intense vertical dynamics during these three seasons, leading to dispersion and dilution processes (and consequently, lower source contributions during the afternoon).

The temporal source strength variation is much more pronounced during weekdays than the weekend, except on Saturday morning. These diel and weekly patterns seem to be consistent with industrial source activities.

\subsubsection{Natural gas and background factor}

The profile of Factor 6, shown in Fig. 8f, is mainly dominated by ethane with around $45 \%$ of its variability explained by this factor. It also contains propane (14.7\%) and light alkanes (butanes), which are key long-lived compounds known to be associated with natural gas leakages. Such species have already been identified in the natural gas experiment (see Sect. 2.4.2, Fig. 4), thus allowing to confirm the identification of this profile. The diel pattern of this factor is mainly based on the diurnal variation of ethane, which is characterized by a nighttime maximum and a midafternoon minimum. Mainly due to its low reactivity, the behavior of ethane can be interpreted as homogeneous species levels during the night under a shallow inversion layer, then followed by concentration reductions caused by the increase of the PBL and vertical mixing - leading to dispersion and dilution processes. Average contributions of this factor were significantly higher when the PBL was low $\left(\sim 11.0-14.0 \mu \mathrm{g} \mathrm{m}^{-3}\right)$ and lower when the PBL was high $\left(\sim 6.0 \mu \mathrm{g} \mathrm{m}^{-3}\right)$.

This F6 profile is also characterized by the presence of oxidized pollutants (OVOCs including acetone and methanol) and aromatic compounds (like benzene), which have relatively long atmospheric residence times of respectively 53 , 12 and 9 days (assuming $\mathrm{OH}=2.0 \times 10^{6}$ molecules $\mathrm{cm}^{-3}$ ) (Atkinson, 2000). Because of their low reactivity, all the species of this factor tend to accumulate in the atmosphere and show significant background levels, especially in the Northern Hemisphere. The resulting emissions can be considered as a partly aged background air, implying a possible regional background and/or a long-range (intercontinental) transport.

The average contribution of this mixed source (combining both natural gas and background emissions) is in the range of $9.2 \mu \mathrm{g} \mathrm{m}^{-3}$ during the whole studied period. Lowest source contributions were observed in winter, which does not fit with those reported in the literature. As mentioned in the motor vehicle exhaust and wood-burning sections (Sect. 3.4.1 and 3.4.3, respectively), PMF artefacts cannot be ruled out. Indeed, a problem with the distribution of ethane (considered as the key species of the mixed source) within PMF factors was raised. We assumed that higher ethane contributions were partly assigned to the motor vehicle exhaust and 


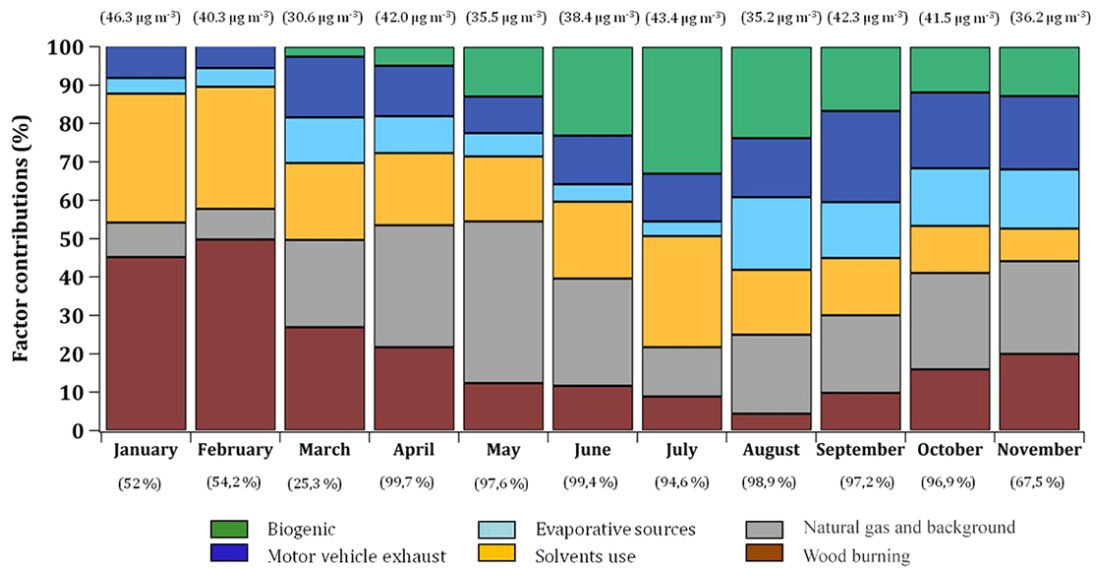

Figure 11. Variations of monthly averaged contributions of the six modeled VOC sources (expressed in percent); (top) average predicted VOC concentration levels per month $\left(\mu \mathrm{g} \mathrm{m}^{-3}\right)$; (bottom) completeness of the data per month $(\%)$.

wood-burning factors. Consequently, we supposed that the natural gas and background factor contributions were underestimated (especially in winter) for the benefits of the woodburning factor (another source significantly contributing during this season).

The highest contributions occur in spring $\left(13.3 \mu \mathrm{g} \mathrm{m}^{-3}\right)$ when the Paris region is mostly influenced by prevailing air masses originating from the north and the northeast parts of Europe passing over Germany and the Benelux area (see Fig. 5). These continental imports constitute background events, which significantly impact baseline levels of ethane and oxygenated species. Slightly lower reconstructed mass contributions of this factor F6 were also observed in autumn. This fact can be explained by the consumption of natural gas (for home heating) during this season as average temperatures are progressively going down. No significant continental influences occur during the fall period as main air masses are coming from the west, south and southeast sectors, thus illustrating the importance of local pollution emissions during this season.

\subsection{VOC source contributions}

PMF simulations revealed the significant contribution of six VOC emission sources (e.g., five specific factor profiles and a mixed one, for which the natural gas source could not be isolated from background emissions). This source apportionment (SA) analysis concluded that the predominant sources at the receptor site were road traffic-related activities (including motor vehicle exhaust, with $15 \%$ of the TVOC mass on the annual average, and evaporative sources, with $10 \%$ ), with the remaining sources from natural gas and background $(23 \%)$, solvent use $(20 \%)$, wood-burning (17\%) and biogenic activities $(15 \%)$. Each modeled factor exhibits distinct patterns due to the variations of the different source emissions and meteorological conditions. Monthly averaged contributions (expressed in percent) of these factors to TVOC mass are reported in Fig. 11. Seasonal variations of the individual sources have already been discussed in the previous sections. Therefore, only the most important features are reported here.

Road traffic emissions were identified by PMF simulations to be the main source of VOCs in Paris. The sum of motor vehicle exhaust and evaporative source contributions accounted for a quarter of the TVOC mass. It showed higher contributions at the end of the year (21 and $15 \%$, respectively), which is still consistent with the study from Bressi et al. (2014) and with long-term black carbon measurements (Petit et al., 2015) linked to enhanced traffic during autumn in Paris. Most importantly, it was observed that the woodburning source exhibited a significant contribution in winter months (almost $50 \%$ in January and February), which is still in agreement with wood-burning-related particle emissions (Favez et al., 2009). The biogenic source also displayed a significant contribution $(\sim 30 \%)$ in summer (mainly due to the weight of oxygenated species in the factor profile). The solvent use source displayed high contributions during winter months ( $\sim 33 \%$, due to a lower PBL height and slower photochemical reactions during that period) and in July (due to the evaporation of solvents controlled by temperature). The source mixing natural gas and background showed a higher proportion in springtime $(\sim 34 \%)$ and lower proportions during autumn $(\sim 25 \%)$. This conclusion can be explained by pollution events that are both related to air masses imported from continental Europe (see Fig. 5) and/or specific meteorological conditions (low temperatures involving the use of home heating), respectively.

The reactivity of each modeled factor has also been investigated by considering the factor concentration of each species with their $\mathrm{OH}$ rate constant $\left(k_{\mathrm{OH}}\right)$ (Atkinson and Arey, 2003) and is reported in relative (and absolute) contributions in Fig. 12. Among all the emission sources identified by PMF, solvent use and motor vehicle exhaust factors 


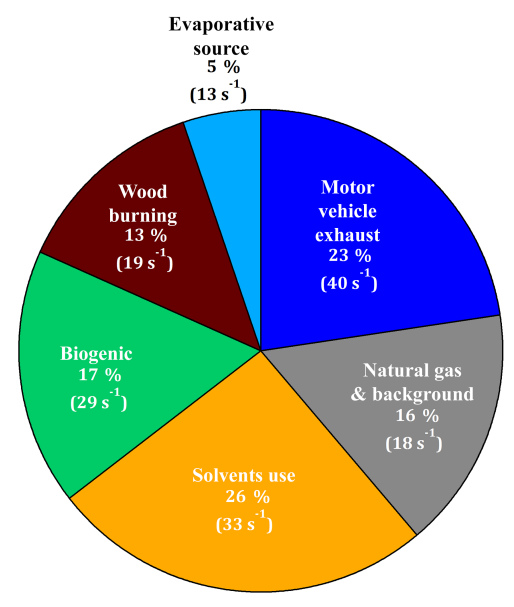

Figure 12. Relative and absolute contributions of reactivity of each PMF factors (percent and per second, respectively).

appear as the main reactive sources $\left(26 \%\left(33 \mathrm{~s}^{-1}\right)\right.$ and $23 \%$ $\left(40 \mathrm{~s}^{-1}\right)$, respectively). This can be explained by high constant rates of aromatics and alkenes mainly associated with these two emission sources. The contribution of the biogenic source is surprisingly weak (17\%). Although isoprene is an extremely reactive species, this factor exhibits a high weight of OVOCs for which constant rates can be low. Instead, the relative contribution of the mixed source natural gas and background is surprisingly high (16\%) due to the presence of aromatics (toluene and xylenes) in the factor profile. The lower contribution of reactivity is represented by the evaporative sources factor $\left(5 \%\left(13 \mathrm{~s}^{-1}\right)\right)$ which contains more stable gases (propane, butanes).

\subsection{Comparison with previous SA studies performed in Paris}

Based on 1-year daily $\mathrm{PM}_{2.5}$ measurements (September 2009-September 2010), Bressi et al. (2014) also conducted an SA analysis using the PMF method (EPA PMF 3.0) with the aim of identifying and characterizing major fine aerosols emission sources within the Paris area. Seven factors, namely ammonium sulfate (A.S.)-rich, ammonium nitrate (A.N.)-rich factors, heavy oil combustion, road traffic, biomass burning, marine aerosols and metal industry were identified. Special attention is paid here to common modeled factor categories.

Primarily of local origin, the road traffic source (resulting from exhaust and non-exhaust processes) constitutes approximately $14 \%$ of $\mathrm{PM}_{2.5}$ mass $\left(\sim 2.1 \mu \mathrm{g} \mathrm{m}^{-3}\right.$, on average) over the whole sampling period. Its annual contribution was considered as significant but surprisingly low given the high traffic density in Paris and its surroundings. It exhibits stable averaged contributions throughout the year, with a smaller proportion in winter $\left(6 \%, 1.3 \mu \mathrm{g} \mathrm{m}^{-3}\right)$ and higher in autumn $\left(19 \%, 2.5 \mu \mathrm{g} \mathrm{m}^{-3}\right)$. This temporal source varia- tion is still in agreement with the seasonal cycle of the road traffic source (combining motor vehicle exhaust and evaporative running losses) issued from our VOC PMF analysis (see Sect. 3.4.1 and 3.4.2). The second common wood-burning source is estimated for the first time over long periods and contributes to around $12 \%\left(1.8 \mu \mathrm{g} \mathrm{m}^{-3}\right)$ of the total $\mathrm{PM}_{2.5}$ mass. As expected, higher contributions were significantly observed during winter $\left(22 \%, 4.7 \mu \mathrm{g} \mathrm{m}^{-3}\right)$ and in autumn $\left(18 \%, 2.4 \mu \mathrm{g} \mathrm{m}^{-3}\right)$. This finding is still consistent with the seasonal pattern of the wood-burning VOC source. Because of the daily time resolution of filter sampling, no diurnal variation of modeled sources was reported in Bressi et al. (2014), thus limiting any additional comparison with this study.

Based on 1-month VOC measurements (25 May14 June 2007) performed at the LHVP site, Gaimoz et al. (2011) also conducted a PMF analysis with the aim of identifying and apportioning major VOC sources in Paris. Seven factors, namely vehicle exhaust, fuel evaporation, remote industrial sources, natural gas and background, local sources, biogenic and fuel evaporation and wood-burning, were found. For an appropriate comparison between this study and our work, special attention is paid here to the modeled speciation profiles and source contributions.

Chemical profiles from Gaimoz et al. (2011) revealed consistent findings with this study. The fuel evaporation factor is mainly composed of butanes, propane and ethane, whereas the vehicle exhaust factor includes iso-pentane, benzene, toluene, $\mathrm{C}_{8}$ and $\mathrm{C}_{9}$ aromatics and in lower proportions ethylene, propene and acetylene. These observations are consistent with modeled evaporative sources and motor vehicle exhaust profiles obtained in this work. A biogenic and fuel evaporation source is also identified and essentially made of isoprene, methanol, acetone and a high proportion of iso-pentane, suggesting that this factor is mixing up biotic emissions and road traffic activities. Highly dependent on (continental) air-mass origins, a remote industrial factor (related to industrial activities and long-range transport of secondary VOCs) is found to exhibit high contributions of OVOCs (methanol, acetone), aromatic species (toluene, $\mathrm{C}_{8}-$ $\mathrm{C}_{9}$ aromatics) and some light alkanes. Our PMF study emphasized a solvent use source, for which these aforementioned compounds were observed, in addition to benzene. The wood-burning source includes only a high contribution of acetonitrile although ethylene, acetylene and benzene are significantly emitted, in accordance with findings from the fireplace experiment (see Sect. 2.4.2, Fig. 3). The mixed natural gas and background source is especially driven by ethane, methanol and acetone. No aromatic species appear in this factor profile. Finally, the local source (LPG - liquefied petroleum gas) including propane and pentanes seems to be associated with fuel evaporation sources. These kinds of emissions have been included in the evaporative sources factor.

During May-June 2007, Gaimoz et al. (2011) concluded that the major VOC sources were related to road traffic emis- 

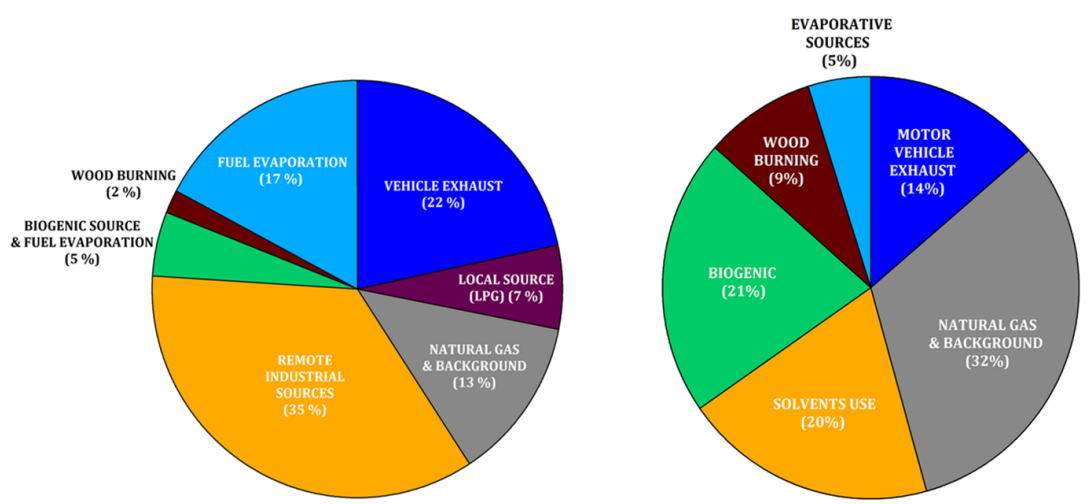

Figure 13. Relative contributions to the TVOC mass of seven and six PMF sources identified from 25 May to 14 June 2007 (Gaimoz et al., 2011 - left pie chart) and 2010 (this study - right pie chart), respectively.

sions ( $\sim 39 \%$ of the TVOC mass), with the remaining emissions from wood-burning ( $2 \%)$, biogenic and fuel evaporation $(5 \%)$, remote industrial sources $(35 \%)$, natural gas and background $(13 \%)$ and local sources $(7 \%)$ during the whole studied period (Fig. 13, left pie chart). To accurately compare VOC sources proportions between 2007 and 2010 (for a similar combination of hydrocarbons and masses), the contribution of each main factor was recalculated for the specific time period May-June 2010 (Fig. 13, right pie chart).

Significant differences between biogenic and woodburning source contributions could eventually be both explained by the weight of major OVOCs into speciation profiles (relative proportions of methanol, acetaldehyde, acetone in these factors are higher than those of the comparative study) and the differences in temperatures affecting the Paris region. The temperatures recorded in May-June 2007 and 2010 were 20 and $16^{\circ} \mathrm{C}$, respectively. This would partially explain a higher home heating consumption and consequently, a higher contribution of the wood-burning factor in 2010 (9\% vs. $2 \%$ for the previous work). Regarding solvent use source contributions, differences can also be explained by ambient temperatures (as they constitute a relevant indicator in solvent emissions) and by the amount of solvents used in manufactories due to recent regulatory frameworks in place ( $20 \%$ in 2010 vs. $35 \%$ in 2007). The difference of natural gas and background source contributions can be due to the importance of air masses coming from the north and northeast parts of Europe between 25 May and 14 June 2010. These air-mass origins were also observed in 2007 and could have affected remote industrial-related emissions and not the mixed source. Slight differences of the motor vehicle exhaust source between 2007 and 2010 (22\% vs. 14\%) could be explained by densification strategies and technological innovations for reducing car use and emissions. Finally, observed differences for the evaporative sources factor (5\% for 2010 and $17 \%$ in 2007) are related to emissions and high temperatures observed in 2007.

\subsection{Comparison with some European SA studies}

Yearly average contributions of the modeled VOC sources (see Sect. 3.5) were also compared with other SA studies performed within urban areas in Europe and in the world. From the different European SA studies available, only one is based on a long VOC time series, which is strengthening the novelty and the originality of the current study.

Based on 2-year hourly measurements of $\mathrm{C}_{2}-\mathrm{C}_{7} \mathrm{NMHCs}$, Lanz et al. (2008) permitted the identification and characterization of between eight and six emission sources at an urban background site in Zürich (Switzerland) in the years 1993 1994 and 2005-2006. Only measurements from 2005 to 2006 are compared here as they are the most recent observations we have available. Six factors, namely gasoline evaporation, solvents, propane, ethane, wood-burning and fuel combustion were determined using the PMF method. This SA study highlighted the importance of vehicular, solvent use, woodburning and gas leakages emissions. The road traffic-related source included both gasoline evaporation and fuel combustion (motor exhaust) factors. While the first factor is mainly dominated by butanes (iso-/n-) and iso-pentane, the second one is essentially driven by ethane, ethene, propene, benzene and toluene. These two speciation profiles are still consistent with those obtained from this PMF analysis, except for iso-pentane. Considered as a key species of evaporative processes, iso-pentane mostly contributed to the motor vehicle exhaust source (Fig. 8a). It was also identified as one of the main compounds emitted in the highway tunnel experiment (Fig. 2), where measured hydrocarbons were representative of fresh emissions (e.g., fuel combustion). This modeled road traffic source contributed to $26 \%$ of the TVOC mass $(13 \%$ for gasoline evaporation and $13 \%$ for fuel combustion factors), which is in the same order of magnitude as that of our vehicle-related source (25\%). The solvent use factor is characterized by pentanes, $\mathrm{S}$-isohexanes (including 2-methylpentane, 3-methylpentane, 2,2-dimethylbutane, 2,3dimethylbutane) and toluene, in agreement with our solvent 
use VOC profile which also included oxygenated species (not measured in Lanz et al., 2008). This industrial factor accounted for $20 \%$ of the TVOC mass. This source contribution is comparable to what we obtained from January to November 2010 (20\%). The wood-burning factor is mainly dominated by ethylene, acetylene, ethane, benzene and contributed to $16 \%$ of the TVOC mass for the 2005-2006 sampling period. This finding is fairly in agreement with our annual wood-burning contribution. Finally, a natural gas source was also identified and consisted of the combination of two separated factors (ethane with propane). Its annual contribution is evaluated at $35 \%$ of the TVOC mass, whereas our mixed natural gas and background source accounted for $23 \%$. No biogenic source was detected for this comparative study. To sum up, average contributions of the road traffic, solvent use and wood-burning sources matched well between this SA study and our modeled results although the input chemical matrix and sampling dates are different.

The importance of these three anthropogenic sources was often reported in other existing urban SA studies from short-term measurements performed in Europe. For instance, Niedojadlo et al. (2007) (Wuppertal, Germany) paid particular attention to solvent use and road traffic source contributions using the chemical mass balance (CMB) modeling technique. Main results showed that the road traffic source dominated total VOC emissions (more than $50 \%$ of the total mass). In addition, it was considered that the proportion of solvent emissions to TVOC concentrations fell in the range of $\sim 20 \%$ in German cities, which is significantly consistent with Lanz et al. (2008) and with this SA study in Paris.

The consistency in VOC contributions in European urban areas raises the question of their representativity at a larger scale. There are currently many other urban SA studies described in the literature (e.g., Jorquera and Rappenglück, 2004 - Santiago, Chile; Buzcu et al., 2006 - Houston, Texas, USA; Brown et al., 2007 - Los Angeles, California, USA; Cai et al., 2010 - Shanghai, China; Morino et al., 2011 Tokyo, Japan; Yurdakul et al., 2013 - Ankara, Turkey; Zheng et al., 2013 - Mexico). Results of these studies are not detailed here but one common feature for European and global scales is the importance of the road traffic source (between 30 and $50 \%$ ). One difference concerns the industrial sector which plays (in the investigated European cities) a lower role than in studied urban areas from other continents.

Governmental regulations and standards to control pollutants emissions and economic developments may differ between European countries and the rest of the world. The location of sampling points (or distances from main sources) and meteorological conditions can strongly affect VOC concentrations and their respective emission sources in the considered urban environments.

\section{Conclusions}

Within the framework of the EU-F7 MEGAPOLI and PRIMEQUAL-FRANCIPOL research programs, a selection of VOCs were continuously measured in real time at two background urban sites located in downtown Paris (France) from 15 January to 22 November 2010. Assessed hydrocarbons included alkanes, alkenes-alkynes, isoprene, aromatics and OVOCs. The current study allowed evaluating VOC concentration levels in ambient air and describing their temporal (seasonal and diurnal) time courses over a long period of time in the French megacity. It also showed an innovative methodology to identify, quantify and understand the main VOC emission sources in Paris by combining field experiments (near-field and ambient air measurements) with source-receptor statistical modeling. The modeled factor profiles were interpreted with respect to those obtained from literature and from three near-field experiments (inside a highway tunnel, at a fireplace and from a domestic gas flue) performed within the Paris area. These additional measurements helped better characterizing and/or confirming traffic, wood-burning and natural-gas-related sources among the existing different source profiles, which can be directly derived from a PMF modeling analysis. These source profile studies therefore allowed to check the representativity and the robustness of our conclusions. This PMF analysis successfully reconstructed at least $88 \pm 2 \%$ of the measured total VOC mass.

Among the six identified PMF factors, road traffic activities appeared to be the main VOC source in Paris accounting for $25 \%$ of the TVOC mass at the annual scale. This source both included motor vehicle exhaust (15\%) and evaporative sources $(10 \%)$. For the first time, it was also shown that the residential wood-burning source exhibited an important contribution in winter (almost $50 \%$ ) due to cold temperatures during that season (leading to home heating consumption). The biogenic source also displayed a significant contribution $(\sim 30 \%)$ in summer mainly due to the weight of oxygenated species in the factor profile. A solvent source was identified and annually contributed to $20 \%$ of the total VOC mass. Finally, it was also revealed that a source mixing natural gas and background (23\%) could be highly dependent on air-mass origins (especially during continental-influenced periods) and meteorological conditions (temperatures). It exhibited a higher proportion in springtime (34\%, explained by intercontinental imports) and in autumn ( $25 \%$, partly for home heating consumption reasons).

From this initial source apportionment study, natural gas could not be isolated from background emissions by the PMF method, thus leading to a limitation of this analysis. A further work will aim at constraining the reference speciation profile (obtained from domestic gas flue measurements) in order to evaluate the relative contribution of natural gas emissions. Lastly, the quantitative assessment of the contributions from different modeled sources presented in this study will pro- 
vide an independent evaluation of the quality and the relevance of the corresponding emission inventories. In particular, the comparison will be very valuable with the updated local emission inventory (provided by the regional air quality network AIRPARIF) as some discrepancies had been pointed out with its previous version.

\section{Data availability}

All the data presented in this paper are available upon request. Please contact Valérie Gros (valerie.gros@1sce.ipsl.fr) for further information. 
Appendix A: Application of the PMF approach in source apportionment of VOCs in Paris

\section{A1 Data preparation}

Initially, the EPA PMF 5.0 model requires two input datasets: one with the chemical species atmospheric concentrations for each observation point and another with either uncertainties values or parameters for calculating the associated uncertainty.

The initial chemical dataset contains a selection of 19 hydrocarbon species and masses (for a detailed overview, see list of compounds in the Sect. 2.4.1) measured from 15 January to 22 November 2010. NMHCs and OVOCs were, respectively, monitored with GC-FID and PTR-MS instruments belonging to different partners involved during the MEGAPOLI and FRANCIPOL intensive field campaigns. Unfortunately, no intercomparison between these instruments was possible because there was approximately a 1-month delay between both experiments. However, preliminary PMF modeling simulations were performed using only the FRANCIPOL dataset (24 March-22 November). The results have shown similar source profiles (see Sect. S1), as those already described in this paper. Consequently, two datasets (corresponding to MEGAPOLI and FRANCIPOL ones, respectively) were considered to form a single one and use it as an input unified database for the final PMF analysis.

The uncertainty dataset was built upon the equation-based method described by Norris et al. (2014). It requires both MDL (here in $\mu \mathrm{g} \mathrm{m}^{-3}$ ) and the analytical uncertainty $(u$, here in percent) for each considered species. Two sets of MDLs were used, one for each measurement campaign. Slight differences among species MDLs were found for $n$-hexane, aromatics, acetaldehyde and MVK + MACR + ISOPOOHs between both experiments. Of these VOCs, MDLs from the FRANCIPOL campaign were chosen for representativity reasons (as the corresponding dataset represents $\sim 88 \%$ of the total data matrix) to keep consistency in uncertainty calculations. The analytical uncertainties were, respectively, estimated at 15 and $20 \%$ and kept constant over the experiments.

The PMF uncertainty $(\sigma)$ is therefore calculated as follows.

$$
\text { If } \begin{aligned}
X_{i j} & \leq \mathrm{MDL}, \forall j ; X_{i j}=\frac{\mathrm{MDL}}{2} \text { and } \\
\sigma_{i j} & =\frac{5}{6} \times \mathrm{MDL}
\end{aligned}
$$

If $X_{i j} \geq$ MDL, $\forall j ; X_{i j}$ does not change and

$$
\sigma_{i j}=\sqrt{\left(\text { Error Fraction } u \times X_{i j}\right)^{2}+(0.5 \times \mathrm{MDL})^{2}}
$$

MDLs and analytical uncertainties $(u)$ for each VOC are reported in Table A1.

\section{A2 Estimation of the number of PMF factors ( $p)$}

The accurate number of PMF factors ( $p$ values) in models must be ultimately estimated by the user using several exploratory means. Specific parameters were used to determine the appropriate $p$ value such as the assessment of $Q$ values, scaled residuals, predicted vs. observed concentrations interpretation and the physical meaning of factor profiles.

Eight different modeling conditions were examined with $p$ values ranging from 3 to 10 , each simulation being randomly conducted 20 times. The reviewing of the IS (the maximum individual standard deviation) parameter highlighted a slope failure for $p=5$, whereas the IM (the maximum individual column mean) indicator reported another slope failure for $p=6$. Choosing less factors, $p<6$, concatenated three source profiles (attributed to solvent use, natural gas and background emissions, respectively) into a factor, whereas choosing $p=6$ allowed splitting one of them. Opting for $p>6$ did not provide any supplemental physical meaningfulness to existing profiles. The investigation of $r^{2}$ from 10 modeled solutions also reported a slope failure for $p=6$. In addition, only $Q_{\text {true }} / Q_{\text {expected value for }} p=6$ was closer than 1.0 (e.g., 0.94 in comparison with 1.12 for $p=5$ and 0.8 for $p=7$ ), thus suggesting that the six-factor configuration is supposed to be the most optimum solution for this PMF analysis. Finally, this configuration was investigated over all the details. Usually, PMF identifies the best solution by the lowest $Q_{\text {robust }}$ value (e.g., the minimum $Q$ ). Within this analysis, its corresponding PMF solution was not considered due to a lack of physical significance for one factor profile (e.g., solvents). Therefore, another PMF solution closest to the selected $Q_{\text {robust }}$ value was subsequently examined and chosen in terms of interpretability and fitting scores.

\section{A3 Robustness of PMF results}

Further technical and mathematical indicators regarding the six-factor configuration are reported here to assess the robustness and the quality of the final PMF solution. Firstly, the ratio between $Q_{\text {robust }}$ and $Q_{\text {true }}$ reached around 1.0, thus indicating that the modeled results were not biased by peak events. Almost $100 \%$ of the scaled residuals were within $\pm 3 \sigma$ and were normally distributed for all species. In addition, the Kolmogorov-Smirnov (KS) test granted a KS $p$ value very close to zero, thus illustrating a statistically significant test with a $\alpha$ risk of $5 \%$. The correlation between total VOC reconstructed concentrations from all the factors with total VOC observed concentrations is depicted in Fig. A1. With $R^{2}$ very close to 0.9 , almost all variance in the total concentration of the 19 VOCs can be explained by the PMF model.

Almost all the chemical species also displayed good determination coefficients ( $r^{2}$ higher than 0.6 for 15 compounds) between predicted and observed concentrations, with the exception of propane and $n$-hexane showing a fairly reasonable 


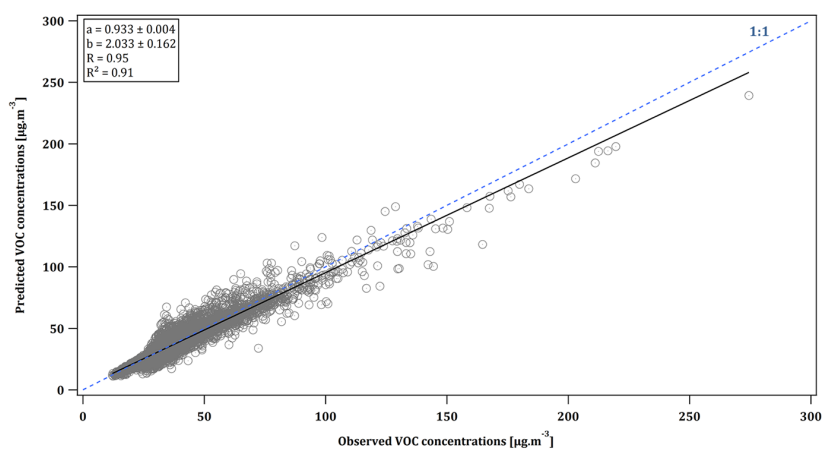

Figure A1. Agreement between total predicted and observed VOC concentrations based on the six-factor PMF solution.

coefficient between 0.5 and 0.6 (due to their 31 and $36 \%$ missing values, respectively). Isoprene and acetonitrile exhibited bad $r^{2}$ values ( 0.29 and 0.06 , respectively) due to either a relatively high number of missing values or a weak additional error, for which sample uncertainties were tripled. Slopes were close to 1.0 for most species (higher than 0.6 for 17 VOCs), except for isoprene (0.5) and acetonitrile (0.02). The limitations of the PMF model to simulate isoprene and acetonitrile have therefore been kept in mind within the reconstructed results description and discussions.

\section{A4 Estimation of model prediction uncertainties}

PMF output uncertainties can be estimated using the error estimation options starting with DISP (d $Q$-controlled displacement of factor elements) and processing to BS (classical bootstrap). These two uncertainty methods are designed to provide key information on the stability and the precision of the chosen PMF solution (Paatero et al., 2014).

The DISP (base model displacement error estimation) assesses the rotational ambiguity of the PMF solution by exploring intervals (minimum and maximum) of source profile values. During the DISP, a minimum $Q$ value is newly calculated (based on the adjustment up and down in factor profile values) and compared with the unadjusted solution $Q$ value.
The difference between the initial $Q$ value and the modified $Q$ value (the so-called $\mathrm{d} Q$ ) should be lower than $\mathrm{d} Q \max$ value, for which four levels (values of 4, 8, 15 and 25) were taken into account. For each $\mathrm{d} Q$ max value, 120 intervals were estimated. The DISP analysis results were considered validated: no error could be detected and no drop of $Q$ was observed. As no swap occurred, the PMF solution was considered sufficiently robust to be used.

The BS (base model bootstrap error estimation) is also used to evaluate the reproducibility of the PMF solution, with a specific focus on the original submatrix F. A further description on the bootstrapping technique is presented in Norris et al. (2014) and in Paatero et al. (2014). A base model bootstrap method was then carried out, executing 100 iterations, using a random seed, a block size of 874 samples (calculated according to the methodology of Politis and White, 2004) and a minimum Pearson correlation coefficient ( $R$ value) of 0.6. All factors were well reproduced through this technique over at least $88 \%$ of runs, thus indicating that BS uncertainties can be interpreted and the number of factors may be appropriate. Consequently, $12 \%$ of runs were redistributed into the different existing factors. No runs were unmapped. Finally, around $91 \%$ of species with the base run profile value were identified within the interquartile range (IQR, e.g., 25th-75th percentile of bootstrap runs) for all factors considered.

Finally, the rotational ambiguity of this six-factor PMF configuration was also investigated using the $F_{\text {peak }}$ parameter. Different $F_{\text {peak }}$ values from -5 to 5 were used to generate a more realistic PMF solution. The results from the nonzero $F_{\text {peak }}$ values were generally consistent with the runs associated with the zero $F_{\text {peak }}$ value (e.g., base model run), thus illustrating a low rotational ambiguity of the final PMF solution. 
Table A1. MDLs and analytical uncertainties $(u)$ for each species used in PMF modeling simulations.

\begin{tabular}{|c|c|c|c|}
\hline Species & $\begin{array}{r}\text { MDL-MEGAPOLI } \\
\mu \mathrm{g} \mathrm{m}^{-3}(\mathrm{ppb})\end{array}$ & $\begin{array}{r}\text { MDL_FRANCIPOL } \\
\mu \mathrm{g} \mathrm{m}^{-3}(\mathrm{ppb})\end{array}$ & $\begin{array}{r}u \\
(\%)\end{array}$ \\
\hline Ethane $^{\mathrm{a}}$ & $0.025(0.020)$ & $0.024(0.019)$ & 15 \\
\hline Ethylene $^{\mathrm{a}}$ & $0.023(0.020)$ & $0.024(0.021)$ & 15 \\
\hline Propane $^{\mathrm{a}}$ & $0.037(0.020)$ & $0.024(0.013)$ & 15 \\
\hline Propene $^{a}$ & $0.035(0.020)$ & $0.024(0.014)$ & 15 \\
\hline Iso-butane $\mathrm{a}^{\mathrm{a}}$ & $0.048(0.020)$ & $0.024(0.010)$ & 15 \\
\hline$N$-butane $\mathrm{a}^{\mathrm{a}}$ & $0.048(0.020)$ & $0.024(0.010)$ & 15 \\
\hline Acetylene $^{\mathrm{a}}$ & $0.022(0.020)$ & $0.024(0.022)$ & 15 \\
\hline Iso-pentane $\mathrm{a}^{\mathrm{a}}$ & $0.060(0.020)$ & $0.024(0.008)$ & 15 \\
\hline$N$-pentane $\mathrm{a}^{\mathrm{a}}$ & $0.060(0.020)$ & $0.024(0.008)$ & 15 \\
\hline$N$-hexane ${ }^{\text {a }}$ & $0.013(0.004)$ & $0.013(0.004)$ & 15 \\
\hline Isoprene $^{\mathrm{a}}$ & $0.024(0.008)$ & $0.024(0.008)$ & 20 \\
\hline Benzene $^{b}$ & $0.071(0.022)$ & $0.071(0.022)$ & 20 \\
\hline Toluene $^{b}$ & $0.240(0.063)$ & $0.240(0.063)$ & 20 \\
\hline Xylenes $+\mathrm{C}_{8}{ }^{\mathrm{b}}$ & $0.259(0.059)$ & $0.259(0.059)$ & 20 \\
\hline Methanol $^{b}$ & $0.317(0.238)$ & $0.330(0.248)$ & 20 \\
\hline Acetonitrile $^{\mathrm{b}}$ & $0.068(0.040)$ & $0.084(0.049)$ & 20 \\
\hline Acetaldehyde $^{\mathrm{b}}$ & $0.167(0.091)$ & $0.167(0.091)$ & 20 \\
\hline Acetone $^{b}$ & $0.092(0.038)$ & $0.118(0.049)$ & 20 \\
\hline $\mathrm{MVK}^{1}+\mathrm{MACR}^{2}+\mathrm{ISOPOOHs}^{3 \mathrm{~b}}$ & $0.020(0.007)$ & $0.020(0.007)$ & 20 \\
\hline$\Sigma \mathrm{VOC}$ & $1.629(0.749)$ & $1.542(0.723)$ & 20 \\
\hline
\end{tabular}

${ }^{1} \mathrm{MVK}=$ methyl vinyl ketone. ${ }^{2} \mathrm{MACR}=$ methacrolein. ${ }^{3}$ ISOPOOHs $=$ isoprene hydroxy hydroperoxides (Rivera-Rios et al., 2014) ${ }^{\text {a }}$ Hydrocarbons measured using a GC-FID by LSCE (MEGAPOLI, LHVP) and AIRPARIF (FRANCIPOL, Les Halles subway station). ${ }^{\mathrm{b}}$ Masses measured using a PTR-MS by LCP (MEGAPOLI, LHVP) and LSCE (FRANCIPOL, LHVP). 


\section{The Supplement related to this article is available online at doi:10.5194/acp-16-11961-2016-supplement.}

Acknowledgements. The authors would like to thank B. TemimeRoussel and N. Marchand from the Laboratoire Chimie Provence (LCP, University of Provence, Marseille, France) for PTR-MS measurements performed at the LHVP site during the MEGAPOLI winter campaign. We would like to thank also M. Beekmann for the coordination of the EU-F7 MEGAPOLI project. We gratefully acknowledge M. M. Squinazzi and Y. Le Moullec for having hosted MEGAPOLI and FRANCIPOL intensive campaigns as well as all colleagues involved in the monitoring process of ambient air measurements, especially Hanitriniala Ravelomanantsoa, Thomas Chaigneau (LHVP) and Laurent Martinon (Laboratoire d'Etude des Particules Inhalées, LEPI). T. Le Priol and J.-F. Petit from the Centre d'Etudes et d'expertise sur les Risques, l'Environnement, la Mobilité et l'Aménagement (CEREMA) are also acknowledged for the logistical assistance in the road tunnel experiment. This work was supported by the CEA, CNRS, IPSL, ADEME, Île-de-France region funds, the EU-PF7 ANR MEGAPOLI and the French PRIMEQUAL-FRANCIPOL, PREQUALIF and CORTEA-CHAMPROBOIS projects. We are thankful to Sabina Assan for helping with the English version of the manuscript.

Edited by: C. Reeves

Reviewed by: two anonymous referees

\section{References}

Airparif: Origine des particules respirées en Île-de-France, Press Pack, available at: http://www.airparif.asso.fr/_pdf/publications/ synthese_particules_110914.pdf (last access: September 2016), 2011.

Airparif: Evolution de la qualité de l'air à Paris entre 2002 et 2012, available at: http://www.airparif.asso.fr/_pdf/publications/ rapport-pdp-130703.pdf (last access: September 2016), 2013.

Airparif: Surveillance et information sur la qualité de l'air en Îlede-France en 2014, available at: http://www.airparif.asso.fr/_pdf/ publications/bilan-2014.pdf (last access: September 2016), 2015.

Ait-Helal, W., Borbon, A., Sauvage, S., de Gouw, J. A., Colomb, A., Gros, V., Freutel, F., Crippa, M., Afif, C., Baltensperger, U., Beekmann, M., Doussin, J.-F., Durand-Jolibois, R., Fronval, I., Grand, N., Leonardis, T., Lopez, M., Michoud, V., Miet, K., Perrier, S., Prévôt, A. S. H., Schneider, J., Siour, G., Zapf, P., and Locoge, N.: Volatile and intermediate volatility organic compounds in suburban Paris: variability, origin and importance for SOA formation, Atmos. Chem. Phys., 14, 10439-10464, doi:10.5194/acp-14-10439-2014, 2014.

Ammoura, L., Xueref-Remy, I., Gros, V., Baudic, A., Bonsang, B., Petit, J.-E., Perrussel, O., Bonnaire, N., Sciare, J., and Chevallier, F.: Atmospheric measurements of ratios between $\mathrm{CO}_{2}$ and co-emitted species from traffic: a tunnel study in the Paris megacity, Atmos. Chem. Phys., 14, 12871-12882, doi:10.5194/acp-1412871-2014, 2014.
Araizaga, A. E., Mancilla, Y., and Mendoza, A.: Volatile Organic Compound Emissions from Light-Duty Vehicles in Monterrey, Mexico: a Tunnel Study, Int. J. Environ. Res., 7, 277-292, 2013.

Atkinson, R.: Atmospheric chemistry of VOCs and $\mathrm{NO}_{x}$, Atmos. Environ., 34, 2063-2101, doi:10.1016/S1352-2310(99)00460-4, 2000.

Atkinson, R. and Arey, J.: Atmospheric Degradation of Volatile Organic Compounds, Chem. Rev., 103, 4605-4638, doi:10.1021/cr0206420, 2003.

Atkinson, R., Baulch, D. L., Cox, R. A., Crowley, J. N., Hampson, R. F., Hynes, R. G., Jenkin, M. E., Rossi, M. J., Troe, J., and IUPAC Subcommittee: Evaluated kinetic and photochemical data for atmospheric chemistry: Volume II - gas phase reactions of organic species, Atmos. Chem. Phys., 6, 3625-4055, doi:10.5194/acp-6-3625-2006, 2006.

Baklanov, A., Lawrence, M., Pandis, S., Mahura, A., Finardi, S., Moussiopoulos, N., Beekmann, M., Laj, P., Gomes, L., Jaffrezo, J.- L., Borbon, A., Coll, I., Gros, V., Sciare, J., Kukkonen, J., Galmarini, S., Giorgi, F., Grimmond, S., Esau, I., Stohl, A., Denby, B., Wagner, T., Butler, T., Baltensperger, U., Builtjes, P., van der Hout, D., van der Gon, H. D., Collins, B., Schluenzen, H., Kulmala, M., Zilitinkevich, S., Sokhi, R., Friedrich, R., Theloke, J., Hummer, U., Jalkinen, L., Halenka, T., Widensholer, A., Pyle, J., and Rossow, W. B.: MEGAPOLI: concept of multi-scale modeling of megacity impact on air quality and climate, Adv. Sci. Res., 4, 115-120, doi:10.5194/asr-4-1152010, 2010.

Barrefors, G. and Petersson, G.: Volatile hydrocarbons from domestic wood burning, Chemosphere, 30, 1551-1556, doi:10.1016/0045-6535(95)00048-D, 1995.

Beekmann, M., Prévôt, A. S. H., Drewnick, F., Sciare, J., Pandis, S. N., Denier van der Gon, H. A. C., Crippa, M., Freutel, F., Poulain, L., Ghersi, V., Rodriguez, E., Beirle, S., Zotter, P., von der Weiden-Reinmüller, S.-L., Bressi, M., Fountoukis, C., Petetin, H., Szidat, S., Schneider, J., Rosso, A., El Haddad, I., Megaritis, A., Zhang, Q. J., Michoud, V., Slowik, J. G., Moukhtar, S., Kolmonen, P., Stohl, A., Eckhardt, S., Borbon, A., Gros, V., Marchand, N., Jaffrezo, J. L., Schwarzenboeck, A., Colomb, A., Wiedensohler, A., Borrmann, S., Lawrence, M., Baklanov, A., and Baltensperger, U.: In situ, satellite measurement and model evidence on the dominant regional contribution to fine particulate matter levels in the Paris megacity, Atmos. Chem. Phys., 15, 9577-9591, doi:10.5194/acp-15-9577-2015, 2015.

Blake, R. S., Monks, P. S., and Ellis, A. M.: Proton Transfer Reaction Mass Spectrometer, Chem. Rev., 109, 861-896, doi:10.1021/cr800364q, 2009.

Borbon, A., Fontaine, H., Veillerot, M., Locoge, N., Galloo, J., and Guillermo, R.: An investigation into the traffic-related fraction of isoprene at an urban location, Atmos. Environ., 35, 3749-3760, doi:10.1016/S1352-2310(01)00170-4, 2001.

Bressi, M., Sciare, J., Ghersi, V., Bonnaire, N., Nicolas, J. B., Petit, J.-E., Moukhtar, S., Rosso, A., Mihalopoulos, N., and Féron, A.: A one-year comprehensive chemical characterisation of fine aerosol $\left(\mathrm{PM}_{2.5}\right)$ at urban, suburban and rural background sites in the region of Paris (France), Atmos. Chem. Phys., 13, 78257844, doi:10.5194/acp-13-7825-2013, 2013.

Bressi, M., Sciare, J., Ghersi, V., Mihalopoulos, N., Petit, J.-E., Nicolas, J. B., Moukhtar, S., Rosso, A., Féron, A., Bonnaire, N., Poulakis, E., and Theodosi, C.: Sources and geographical ori- 
gins of fine aerosols in Paris (France), Atmos. Chem. Phys., 14, 8813-8839, doi:10.5194/acp-14-8813-2014, 2014.

Brown, S. G., Frankel, A., and Hafner, H. R.: Source apportionment of VOCs in the Los Angeles area using positive matrix factorization, Atmos. Environ., 41, 227-237, doi:10.1016/j.atmosenv.2006.08.021, 2007.

Butler, D.: Megacity project seeks to gauge urban pollution, Nature, 455, 142-143, doi:10.1038/455142b, 2008.

Buzcu, B. and Fraser, M. P.: Source identification and apportionment of volatile organic compounds in Houston, TX, Atmos. Environ., 40, 2385-2400, doi:10.1016/j.atmosenv.2005.12.020, 2006.

Cai, C., Genz, F., Tie, X., Yu, Q., and An, J.: Characteristics and source apportionment of VOC measured in Shanghai, China, Atmos. Environ., 44, 5005-5014, doi:10.1016/j.atmosenv.2010.07.059, 2010.

Carter, W. P. L.: Development of ozone reactivity scales for volatile organic compounds, J. Air Waste Manage. As., 44, 881-899, doi:10.1080/1073161X.1994.10467290, 1994.

Chameides, W. L., Fehsenfeld, F., Rodgers, M. O., Cardelino, C., Martinez, J., Parrish, D., Lonneman, W., Lawson, D. R., Rasmussen, R. A., Zimmerman, P., Greenberg, J., Middleton, P. and Wang, T.: Ozone precursor relationships in the ambient atmosphere, J. Geophys. Res.-Atmos., 97, 6037-6055, doi:10.1029/91JD03014, 1992.

Cornelissen, G. and Gustafsson, Ö.: Sorption of Phenanthrene to Environmental Black Carbon in Sediment with and without Organic Matter and Native Sorbates, Environ. Sci. Technol., 38, 148-155, doi:10.1021/ES034776m, 2004.

Crippa, M., DeCarlo, P. F., Slowik, J. G., Mohr, C., Heringa, M. F., Chirico, R., Poulain, L., Freutel, F., Sciare, J., Cozic, J., Di Marco, C. F., Elsasser, M., Nicolas, J. B., Marchand, N., Abidi, E., Wiedensohler, A., Drewnick, F., Schneider, J., Borrmann, S., Nemitz, E., Zimmermann, R., Jaffrezo, J.-L., Prévôt, A. S. H., and Baltensperger, U.: Wintertime aerosol chemical composition and source apportionment of the organic fraction in the metropolitan area of Paris, Atmos. Chem. Phys., 13, 961-981, doi:10.5194/acp-13-961-2013, 2013.

Deguillaume, L., Beekmann, M., and Derognat, C.: Uncertainty evaluation of ozone production and its sensitivity to emission changes over the Île-de-France region during summer periods, J. Geophys. Res., 113, D02304, doi:10.1029/2007JD009081, 2008.

Directive 2000/69/EC: Directive 2000/69/EC of the European Parliament and of the Council of 16 November 2000 relating to limit values for benzene and carbon monoxide in ambient air, Official Journal of the European Communities, 13 December 2000.

Directive 2008/50/EC: Directive 2008/50/EC of the European Parliament and of the Council of 21 May 2008 on ambient air quality and cleaner air for Europe. Official Journal of the European Communities, 11 June 2008.

Dolgorouky, C., Gros, V., Sarda-Esteve, R., Sinha, V., Williams, J., Marchand, N., Sauvage, S., Poulain, L., Sciare, J., and Bonsang, B.: Total OH reactivity measurements in Paris during the 2010 MEGAPOLI winter campaign, Atmos. Chem. Phys., 12, 95939612, doi:10.5194/acp-12-9593-2012, 2012.

Eurostat: available at: http://ec.europa.eu/eurostat/fr, last access: 30 July 2015.

Evtyugina, M., Alves, C., Calvo, A., Nunes, T., Tarelho, L., Duarte, M., Prozil, S. O., Evtuguin, D. V., and Pio,
C.: VOC emissions from residential combustion of Southern and mid-European woods, Atmos. Environ., 83, 90-98, doi:10.1016/j.atmosenv.2013.10.050, 2014.

Favez, O., Cachier, H., Sciare, J., and Moullec, Y. L.: Characterization and contribution to $\mathrm{PM}_{2.5}$ of semi-volatile aerosols in Paris (France), Atmos. Environ., 41, 7969-7976, doi:10.1016/j.atmosenv.2007.09.031, 2007.

Favez, O., Cachier, H., Sciare, J., Sarda-Estève, R., and Martinon, L.: Evidence for a significant contribution of wood burning aerosols to $\mathrm{PM}_{2.5}$ during the winter season in Paris, France, Atmos. Environ., 43, 3640-3644, doi:10.1016/j.atmosenv.2009.04.035, 2009.

Filella, I. and Peñuelas, J.: Daily, weekly, and seasonal time courses of VOC concentrations in a semi-urban area near Barcelona, Atmos. Environ., 40, 7752-7769, doi:10.1016/j.atmosenv.2006.08.002, 2006.

Fortner, E. C., Zheng, J., Zhang, R., Berk Knighton, W., Volkamer, R. M., Sheehy, P., Molina, L., and André, M.: Measurements of Volatile Organic Compounds Using Proton Transfer Reaction - Mass Spectrometry during the MILAGRO 2006 Campaign, Atmos. Chem. Phys., 9, 467-481, doi:10.5194/acp-9-467-2009, 2009.

Frachon, H.: Utilisation des mesures de concentration de COV pour la validation des émissions et l'amélioration de la prévision de l'ozone - phase 2, Rapport de stage professionnel effectué en collaboration avec AIRPARIF, 2009.

Gaeggeler, K., Prévôt, A. S. H., Dommen, J., Legreid, G., Reimann, S., and Baltensperger, U.: Residential wood burning in an Alpine valley as a source for oxygenated volatile organic compounds, hydrocarbons and organic acids, Atmos. Environ., 42, 8278-8287, doi:10.1016/j.atmosenv.2008.07.038, 2008.

Gaimoz, C., Sauvage, S., Gros, V., Herrmann, F., Williams, J., Locoge, N., Perrussel, O., Bonsang, B., d'Argouges, O., SardaEstève, R., and Sciare, J.: Volatile Organic Compounds sources in Paris in spring 2007. Part II: source apportionment using Positive Matrix Factorization, Environ. Chem., 8, 91-103, doi:10.1071/EN10067, 2011.

Goldstein, A. H., Fan, S. M., Goulden, M. L., Munger, J. W., and Wofsy, S. C.: Emissions of ethene, propene and 1-butene by a midlatitude forest, J. Geophys. Res., 101, 9149-9157, doi:10.1029/96jd00334, 1996.

Gros, V., Sciare, J., and Yu, T.: Air-quality measurements in megacities: focus on gaseous organic and particulate pollutants and comparison between two contrasted cities, Paris and Beijing, C.R. Geosci., 339, 764-774, doi:10.1016/j.crte.2007.08.007, 2007.

Gros, V., Gaimoz, C., Herrmann, F., Custer, T., Williams, J., Bonsang, B., Sauvage, S., Locoge, N., d'Argouges, O., SardaEstève, R., and Sciare, J.: Volatile Organic Compounds sources in Paris in spring 2007. Part I: qualitative analysis, Environ. Chem., 8, 74-90, doi:10.1071/EN10068, 2011.

Guenther, A.: The contribution of reactive carbon emissions from vegetation to the carbon balance of terrestrial ecosystems, Chemosphere, 49, 837-844, doi:10.1016/S00456535(02)00384-3, 2002.

Gurjar, B.: Air quality in megacities, available at: http://www. eoearth.org/view/article/51cbece17896bb431f68e326 (last access: September 2016), 2014. 
Gustafson, P., Barregard, L., Strandberg, B., and Sallsten, G.: The impact of domestic wood burning on personal, indoor and outdoor levels of 1.3-butadiene, benzene, formaldehyde and acetaldehyde, J. Environ. Monitor., 9, 23-32, doi:10.1039/B614142K, 2007.

Holzinger, R., Warneke, C., Hansel, A., Jordan, A., Lindinger, W., Scharffe, H., Schade, G., and Crutzen, P. J.: Biomass burning as a source of formaldehyde, acetaldehyde, acetone, acetonitrile and hydrogen cyanide, Geophys. Res. Lett., 26, 1161-1164, doi:10.1029/1999GL900156, 1999.

IARC: Outdoor air pollution a leading environmental cause of cancer deaths, Press Release no. 221, 2013.

Jorquera, H. and Rappenglück, B.: Receptor modeling of ambient VOC at Santiago, Chile, Atmos. Environ., 38, 4243-4263, doi:10.1016/j.atmosenv.2004.04.030, 2004.

Karl, T., Jobson, T., Kuster, W. C., Williams, E., Stutz, J., Shetter, R., Hall, S. R., Goldan, P., Fehsenfeld, F., and Lindinger, W.: Use of proton-transfer-reaction mass spectrometry to characterize volatile organic compound sources at the La Porte super site during the Texas Air Quality Study 2000, J. Geophys. Res.Atmos., 235, 4508, doi:10.1029/2002JD003333, 2003.

Kesselmeier, J. and Staudt, M.: Biogenic Volatile Organic Compounds (VOC): An overview on Emission, Physiology and Ecology, Atmos. Chem., 33, 23-88, 1999.

Langford, B., Nemitz, E., House, E., Phillips, G. J., Famulari, D., Davison, B., Hopkins, J. R., Lewis, A. C., and Hewitt, C. N.: Fluxes and concentrations of volatile organic compounds above central London, UK, Atmos. Chem. Phys., 10, 627-645, doi:10.5194/acp-10-627-2010, 2010.

Lanz, V. A., Hueglin, C., Buchmann, B., Hill, M., Locher, R., Staehelin, J., and Reimann, S.: Receptor modeling of $\mathrm{C}_{2}-\mathrm{C}_{7}$ hydrocarbon sources at an urban background site in Zurich, Switzerland: changes between 1993-1994 and 2005-2006, Atmos. Chem. Phys., 8, 2313-2332, doi:10.5194/acp-8-2313-2008, 2008.

Lanz, V. A., Henne, S., Staehelin, J., Hueglin, C., Vollmer, M. K., Steinbacher, M., Buchmann, B., and Reimann, S.: Statistical analysis of anthropogenic non-methane VOC variability at a European background location (Jungfraujoch, Switzerland), Atmos. Chem. Phys., 9, 3445-3459, doi:10.5194/acp-9-3445-2009, 2009.

Legreid, G., Reimann, S., Steinbacher, M., Staehelin, J., Young, D., and Stemmler, K.: Measurements of OVOCs and NMHCs in a Swiss Highway Tunnel for Estimation of Road Transport Emissions, Environ. Sci. Technol., 41, 7060-7066, doi:10.1021/es062309+, 2007.

Lelieved, J., Evans, J. S., Fnais, M., Giannadaki, D., and Pozzer, A.: The contribution of outdoor air pollution sources to premature mortality on a global scale, Nature, 525, 367-371, doi:10.1038/nature15371, 2015.

Leuchner, M., Gubo, S., Schunk, C., Wastl, C., Kirchner, M., Menzel, A., and Plass-Dülmer, C.: Can positive matrix factorization help to understand patterns of organic trace gases at the continental Global Atmosphere Watch site Hohenpeissenberg?, Atmos. Chem. Phys., 15, 1221-1236, doi:10.5194/acp-15-12212015, 2015.

Liu, S. C., Trainer, M., Fehsenfeld, F. C., Parrish, D. D., Williams, E. J., Fahey, D. W., Hübler, G., and Murphy, P. C.: Ozone production in the rural troposphere and the implications for regional and global ozone distributions, J. Geophys. Res.Atmos., 92, 4191-4207, doi:10.1029/JD092Id04P04191, 1987.

Logan, J. A., Prather, M. J., Wofsy, S. C., and McElroy, M. B.: Tropospheric chemistry: A global perspective, J. Geophys. Res., 86, 7210-7254, doi:10.1029/JC086Ic08P07210, 1981.

Mathé, F.: Evolution de la classification et des critères d'implantation des stations de mesure de la qualité de l'air - Participation à la réactualisation du guide de classification des stations, LCSQA-Mines Douai Report, 2010.

Météo-France: Bulletins Climatologiques Mensuels pour Paris et sa petite couronne de Janvier à Novembre 2010, available at: https: //donneespubliques.meteofrance.fr, last access: July 2015.

Montero, L., Duane, M.,Manfredi, U., Astorga, C., Martini, G., Carriero, M., Krasenbrink, A., and Larsen, B.-R.: Hydrocarbon emission fingerprints from contemporary vehicle/engine technologies with conventional and new fuels, Atmos. Environ., 44, 2167-2175, 2010.

Morino, Y., Ohara, T., Yokouchi, Y., and Ooki, A.: Comprehensive source apportionment of volatile organic compounds using observational data, two receptor models, and an emission inventory in Tokyo metropolitan area, J. Geophys. Res., 116, D0211, doi:10.1029/2010JD014762, 2011.

Na, K.: Determination of VOC source signature of vehicle exhaust in a traffic tunnel, J. Environ. Manage., 81, 392-398, doi:10.1016/j.jenvman.2005.11.004, 2006.

Nalin, F., Golly, B., Besombes, J.-L., Pelletier, C., Aujay, R., Verlhac, S., Dermigny, A., Fievet, A., Karoski, N., Dubois, P., Collet, S., Favez, O., and Albinet, A.: Fast oxidation processes from 90 emission to ambient air introduction of aerosol emitted by residential log wood stoves, Atmos. Environ., 143, 15-26, doi:10.1016/j.atmosenv.2016.08.002, 2016.

Ng, N. L., Kroll, J. H., Chan, A. W. H., Chhabra, P. S., Flagan, R. C., and Seinfeld, J. H.: Secondary organic aerosol formation from m-xylene, toluene, and benzene, Atmos. Chem. Phys., 7, 3909-3922, doi:10.5194/acp-7-3909-2007, 2007.

Niedojadlo, A., Heinz Becker, K., Kurtenbach, R., and Wiesen, P.: The contribution of traffic and solvent use to the total NMVOC emission in a German city derived from measurements and CMB modelling, Atmos. Environ., 41, 7108-7126, doi:10.1016/j.atmosenv.2007.04.056, 2007.

Norris, G., Duvall, R., Brown, S., and Bai, S.: EPA Positive Matrix Factorization (PMF) 5.0: Fundamentals \& User Guide, Prepared for the US, Environmental Protection Agency (EPA), Washington, DC, by the National Exposure Research Laboratory, Research Triangle Park; Sonoma Technology, Inc., Petaluma, 2014.

Paatero, P. and Tapper, U.: Positive Matrix Factorization: A non-negative factor model with optimal utilization of error estimates of data values, Environmetrics, 5, 111-126, doi:10.1002/env.3170050203, 1994.

Paatero, P. and Hopke, P. K.: Discarding or downweighting highnoise variables in factor analytic models, Anal. Chim. Acta, 490, 277-289, doi:10.1016/S0003-2670(02)01643-4, 2003.

Paatero, P., Eberly, S., Brown, S. G., and Norris, G. A.: Methods for estimating uncertainty in factor analytic solutions, Atmos. Meas. Tech., 7, 781-797, doi:10.5194/amt-7-781-2014, 2014.

Passant, N. R.: Speciation of UK emissions of non-methane volatile organic compounds, AEA Technology, report No. AEAT/ENV/R/0545, 2002. 
Petit, J.-E., Favez, O., Sciare, J., Crenn, V., Sarda-Estève, R., Bonnaire, N., Mocnik, G., Dupont, J.-C., Haeffelin, M., and LeozGarziandia, E.: Two years of near real-time chemical composition of submicron aerosols in the region of Paris using an Aerosol Chemical Speciation Monitor (ACSM) and a multiwavelength Aethalometer, Atmos. Chem. Phys., 15, 2985-3005, doi:10.5194/acp-15-2985-2015, 2015.

Polissar, A. V., Hopke, P. K., Paatero, P., Malm, W. C., and Sisler, J. F.: Atmospheric aerosol over Alaska, 2. Elemental Composition and Sources, J. Geophys. Res.-Atmos., 103, 19045-19057, doi:10.1029/98JD01212, 1998.

Politis, D. N. and White, H.: Automatic block-length selection for the dependent bootstrap, Econometrics Reviews, 23, 53-70, doi:10.1081/ETC-120028836, 2004.

Purvis, C. R. and McCrillis, R. C.: Fine Particulate Matter (PM) and Organic Speciation of Fireplace Emissions, Environ. Sci. Technol., 34, 1653-1658, doi:10.1021/es981006f, 2000.

Rivera-Rios, J. C., Nguyen, T. B., Crounse, J. D., Jud, W., St. Clair, J. M., Mikoviny, T., Gilman, J. B., Lerner, B. M., Kaiser, J. B., de Gouw, J., Wisthaler, A., Hansel, A., Wennberg, P. O., Seinfeld, J. H., and Keutsch, F. N.: Conversion of hydroperoxides to carbonyls in field and laboratory instrumentation: Observational biais in diagnosing pristine versus anthropogenically controlled atmospheric chemistry, Geophys. Res. Lett., 41, 8645-8651, doi:10.1002/2014GL061919, 2014.

Roukos, J., Plaisance, H., Leonardis, T., Bates, M., and Locoge, N.: Development and validation of an automated monitoring system for oxygenated volatile organic compounds and nitrile compounds in ambient air, J. Chromatogr. A., 1216, 8642-8651, doi:10.1016/j.chroma.2009.10.018, 2009.

Sandradewi, J., Prévôt, A. S., Szidat, S., Perron, N., Alfarra, M. R., Lanz, V. A., Weingartner, E., and Baltensperger, U.: Using aerosol light absorption measurements for the quantitative determination of wood burning and traffic emission contributors to particulate matter, Environ. Sci. Technol., 42, 3316-3323, doi:10.1021/es702253m, 2008.

Sauvage, S., Plaisance, H., Locoge, N., Wroblewski, A., Coddeville, P., and Galloo, J.-C.: Long term measurement and source apportionment of non-methane hydrocarbons in three French rural areas, Atmos. Environ., 43, 2430-2441, doi:10.1016/j.atmosenv.2009.02.001, 2009.

Sciare, J., d'Argouges, O., Zhang, Q. J., Sarda-Estève, R., Gaimoz, C., Gros, V., Beekmann, M., and Sanchez, O.: Comparison between simulated and observed chemical composition of fine aerosols in Paris (France) during springtime: contribution of regional versus continental emissions, Atmos. Chem. Phys., 10, 11987-12004, doi:10.5194/acp-10-11987-2010, 2010.

Sciare, J., d'Argouges, O., Sarda-Estève, R., Gaimoz, C., Dolgorouky, C., Bonnaire, N., Favez, O., Bonsang, B., and Gros, V.: Large contribution of water-insoluble secondary organic aerosols in the region of Paris (France) during wintertime, J. Geophys. Res.-Atmos., 116, doi:10.1029/2011JD015756, 2011.

Seco, R., Peñuelas, J., Filella, I., Llusia, J., Schallhart, S., Metzger, A., Müller, M., and Hansel, A.: Volatile organic compounds in the western Mediterranean basin: urban and rural winter measurements during the DAURE campaign, Atmos. Chem. Phys., 13, 4291-4306, doi:10.5194/acp-13-4291-2013, 2013.
Shao, M., Lu, S., Liu, Y., Xie, X., Chang, C., Huang, S., and Chen, Z.: Volatile organic compounds measured in summer in Beijing and their role in ground-level ozone formation, J. Geophys. Res.-Atmos., 114, D00G06, doi:10.1029/2008JD010863, 2009.

Sillman, S.: The relation between ozone, $\mathrm{NO}_{x}$ and hydrocarbons in urban and polluted rural environments, Atmos. Environ., 33, 1821-1845, doi:10.1016/S1352-2310(98)00345-8, 1999.

Sinha, V., Kumar, V., and Sarkar, C.: Chemical composition of premonsoon air in the Indo-Gangetic Plain measured using a new air quality facility and PTR-MS: high surface ozone and strong influence of biomass burning, Atmos. Chem. Phys., 14, 59215941, doi:10.5194/acp-14-5921-2014, 2014.

Skyllakou, K., Murphy, B. N., Megaritis, A. G., Fountoukis, C., and Pandis, S. N.: Contributions of local and regional sources to fine PM in the megacity of Paris, Atmos. Chem. Phys., 14, 23432352, doi:10.5194/acp-14-2343-2014, 2014.

Solomon, S. J., Custer, T., Schade, G., Soares Dias, A. P., and Burrows, J.: Atmospheric methanol measurement using selective catalytic methanol to formaldehyde conversion, Atmos. Chem. Phys., 5, 2787-2796, doi:10.5194/acp-5-2787-2005, 2005.

Stein, A. F., Draxler, R. R., Rolph, G. D., Stunder, B. J. B., Cohen, M. D., and Ngan, F.: NOAA's HYSPLIT Atmospheric Transport and Dispersion Modeling System, B. Am. Meteorol. Soc., 96, 2059-2077, doi:10.1175/BAMS-D-14-00110.1, 2015.

Steiner, A. H. and Goldstein, A. L.: Biogenic VOCs, Volatile Organic Compounds in the Atmosphere, Blackwell Publishing, 82128, 2007.

Touaty, M. and Bonsang, B.: Hydrocarbon emissions in a highway tunnel in the Paris area, Atmos. Environ., 34, 985-996, doi:10.1016/S1352-2310(99)00195-8, 2000.

Tsai, P.-J., Shieh, H.-Y., Lee, W.-J., and Lai, S.-O.: Health-risk assessment for workers exposed to Polycyclic Aromatic Hydrocarbons (PAHs) in a carbon black manufacturing industry, Sci. Total Environ., 278, 137-150, doi:10.1016/S0048-9697(01)00643-X, 2001.

Tsigaridis, K. and Kanakidou, M.: Global modelling of secondary organic aerosol in the troposphere: a sensitivity analysis, Atmos. Chem. Phys., 3, 1849-1869, doi:10.5194/acp-3-1849-2003, 2003.

United Nations, World Urbanization Prospects: The 2014 Revision, United Nations publication, ST/ESA/SER.A/352, available at: http://esa.un.org/unpd/wup/Highlights/WUP2014-Highlights. pdf (last access: October 2015), 2014.

Waked, A., Sauvage, S, Borbon, A., Gauduin, J., Pallares, C., Vagnot, M.-P., Léonardis, T., and Locoge, N.: Multi-year levels and trends of non-methane hydrocarbon concentrations observed in ambient air in France, Atmos. Environ., 141, 263-275, doi:10.1016/j.atmosenv.2016.06.059, 2016.

Weingartner, E., Saathoff, H., Schnaiter, M., Streit, N., Bitnar, B., and Baltensperger, U.: Absorption of light by soot particles: determination of the absorption coefficient by means of aethalometers, J. Aerosol Sci., 34, 1445-1463, doi:10.1016/S00218502(03)00359-8, 2003. 
Yurdakul, S., Civan, M., and Gürdal, T.: Volatile organic compounds in suburban Ankara atmosphere, Turkey: Sources and variability, Atmos. Res., 120-121, 298-311, doi:10.1016/j.atmosres.2012.09.015, 2013.
Zheng, J., Garzon, J. P., Huertas, M. E., Zhang, R., Levy, M. Ma, Y., Huertas, J. I., Jardon, R. T., Ruiz, L. G., Tan, H., and Molina, L. T.: Volatile organic compounds in Tijuana during the Cal-Mex 2010 campaign: Measurements and source apportionment, Atmos. Environ., 70, 521-531, doi:10.1016/j.atmosenv.2012.11.030, 2013. 